\title{
LPS receptor subunits have antagonistic roles in epithelial apoptosis and colonic carcinogenesis
}

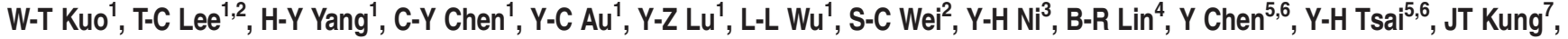 \\ F Sheu ${ }^{8}$, L-W Lin ${ }^{9}$ and LC-H Yu,
}

Colorectal carcinoma (CRC) is characterized by unlimited proliferation and suppression of apoptosis, selective advantages for tumor survival, and chemoresistance. Lipopolysaccharide (LPS) signaling is involved in both epithelial homeostasis and tumorigenesis, but the relative roles had by LPS receptor subunits CD14 and Toll-like receptor 4 (TLR4) are poorly understood. Our study showed that normal human colonocytes were $\mathrm{CD} 14^{+} \mathrm{TLR}^{-}$, whereas cancerous tissues were $\mathrm{CD} 14^{+} \mathrm{TLR} 4^{+}$, by immunofluorescent staining. Using a chemical-induced CRC model, increased epithelial apoptosis and decreased tumor multiplicity and sizes were observed in TLR4-mutant mice compared with wild-type (WT) mice with CD14 ${ }^{+} \mathrm{TLR}^{+}$colonocytes. WT mice intracolonically administered a TLR4 antagonist displayed tumor reduction associated with enhanced apoptosis in cancerous tissues. Mucosa-associated LPS content was elevated in response to CRC induction. Epithelial apoptosis induced by LPS hypersensitivity in TLR4-mutant mice was prevented by intracolonic administration of neutralizing anti-CD14. Moreover, LPSinduced apoptosis was observed in primary colonic organoid cultures derived from TLR4 mutant but not WT murine crypts. Gene silencing of TLR4 increased cell apoptosis in WT organoids, whereas knockdown of CD14 ablated cell death in TLR4-mutant organoids. In vitro studies showed that LPS challenge caused apoptosis in Caco-2 cells (CD14 $\left.{ }^{+} \mathrm{TLR}^{-}\right)$in a CD14-, phosphatidylcholine-specific phospholipase C-, sphingomyelinase-, and protein kinase C- $\zeta-$ dependent manner. Conversely, expression of functional but not mutant TLR4 (Asp299Gly, Thr399lle, and Pro714His) rescued cells from LPS/CD14-induced apoptosis. In summary, CD14-mediated lipid signaling induced epithelial apoptosis, whereas TLR4 antagonistically promoted cell survival and cancer development. Our findings indicate that dysfunction in the CD14/TLR4 antagonism may contribute to normal epithelial transition to carcinogenesis, and provide novel strategies for intervention against colorectal cancer.

Cell Death and Differentiation (2015) 22, 1590-1604; doi:10.1038/cdd.2014.240; published online 30 January 2015

Colorectal tumorigenesis proceeds via the accumulation of genetic and epigenetic alterations that promote unlimited cell proliferation, self-sufficient growth signaling, neovascularization, tissue invasion, and resistance to cell death. ${ }^{1}$ The transformation of normal epithelium into colorectal carcinomas (CRC) is associated with the progressive inhibition of apoptosis; this confers a selective advantage for tumor cell survival and chemoresistance. ${ }^{2,3}$ It is generally believed that sufficient epithelial apoptosis may hamper colon cancer formation in terms of incidence and growth rate. ${ }^{4-6}$ Direct evidence for this was recently reported in mice deficient in pro-apoptotic molecules. ${ }^{7,8}$ To date, the regulatory mechanisms of physiological apoptosis to eliminate premalignant cells in the gut remain incompletely understood.

Intestinal homeostasis is maintained by the dynamic, yet strictly regulated, turnover of epithelial cells. An imbalance in epithelial death versus survival/proliferative responses may lead to barrier dysfunction, chronic inflammation, and tumorigenesis. ${ }^{9,10}$ Accumulating evidence indicates that gut microbiota and bacterial lipopolysaccharide (LPS) have critical roles in epithelial cell renewal under baseline conditions and on injury, ${ }^{11,12}$ and are involved in the pathogenesis of colitis-associated CRC as well. ${ }^{13-15}$ Given the juxtaposition of commensal bacteria and the gut mucosa, it has been assumed that normal epithelial cells are not equipped with LPS receptor complexes (CD14/TLR4/MD2) or express altered forms of receptors and signaling molecules to achieve immunotolerance. ${ }^{15}$ Constitutive expression of CD14 was reported in the presence of negligible-to-low levels of Toll-like receptor 4 (TLR4) in normal human colonocytes, ${ }^{16-18}$ whereas strong TLR4 immunoreactivity was detected in CRC. ${ }^{18,19}$ Nevertheless, divergent cellular responses to LPS (death versus survival) have been reported among human $\mathrm{CRC}$ cell lines. Several laboratories, using Caco-2 cells, have

${ }^{1}$ Graduate Institute of Physiology, National Taiwan University College of Medicine, Taipei, Taiwan; ${ }^{2}$ Department of Internal Medicine, National Taiwan University College of Medicine, Taipei, Taiwan; ${ }^{3}$ Department of Pediatrics, National Taiwan University College of Medicine, Taipei, Taiwan; ${ }^{4}$ Department of Surgery, National Taiwan University College of Medicine and Hospital, Taipei, Taiwan; ${ }^{5}$ Department of Surgery, Far Eastern Memorial Hospital, New Taipei, Taiwan; ${ }^{6}$ Department of Chemical Engineering and Material Science, Yuan-Ze University, Tao-Yuan, Taiwan; ${ }^{7}$ Institute of Molecular Biology, Academia Sinica, Taipei, Taiwan; ${ }^{8}$ Department of Horticulture, National Taiwan University, Taipei, Taiwan and ${ }^{9}$ Department of Pathology, National Taiwan University Hospital, Yunlin Branch, Yunlin, Taiwan

${ }^{*}$ Corresponding author: L C-H Yu, Graduate Institute of Physiology, National Taiwan University College of Medicine, Suite 1020, 1 Jen-Ai Road, Section I, Taipei 100, Taiwan R.O.C. Tel: +886 223123456 ext.88237; Fax: +886 2 23964350; E-mail: Ichyu@ntu.edu.tw

Abbreviations: LPS, lipopolysaccharide; TLR, Toll-like receptor; CRC, colorectal carcinoma; WT, wild type; AOM/DSS, azoxymethane/dextran sulfate sodium; CO, commensal overgrowth; RT-PCR, reverse transcription-PCR; TUNEL, terminal deoxynucleotidyl transferase dUTP-biotin nick end labeling; DMEM, Dulbecco's modified Eagle's medium; PC-PLC, phosphatidylcholine-specific phospholipase C; SMase, sphingomyelinase; PKC, protein kinase C; MyD88, myeloid differentiation factor; MAPK, mitogen-activated protein kinase; $1 \kappa \mathrm{B}$, inhibitor of $\kappa \mathrm{B} ; \mathrm{NF} \kappa \mathrm{B}$, nuclear factor- $\kappa \mathrm{B}$; IRF3, interferon regulatory factor 3 ; $\mathrm{PMB}$, polymyxin $\mathrm{B}$

Received 23.4.14; revised 24.11.14; accepted 22.12.14; Edited by A Villunger; published online 30.1.15 
described increases in apoptotic cell death following apical LPS challenge, ${ }^{20,21}$ whereas others have documented enhanced survival and proliferative responses of HT29 and SW480 cells to LPS. ${ }^{22,23}$ Here we hypothesize that differing expression patterns of LPS receptor subunits on epithelial surfaces may have a determining role in cell death versus survival.

CD14, as the membrane-bound subunit of LPS receptor complex and lacking a cytoplasmic tail, has traditionally been regarded as merely a binding component for transferring LPS to TLR4. TLR4 subsequently activates downstream adaptors and signaling pathways, such as myeloid differentiation factor (MyD88), mitogen-activated protein kinases (MAPKs), inhibitor of $\kappa \mathrm{B}\left(\mathrm{I}_{\kappa \mathrm{B}}\right) /$ nuclear factor- $\kappa \mathrm{B}(\mathrm{NF} \kappa \mathrm{B})$, and interferon regulatory factor 3 (IRF3). ${ }^{24,25}$ Recent findings in monocytes have indicated that LPS/CD14 binding triggers a cascade of lipid messenger signals before TLR4 trafficking to lipid rafts for complex formation. CD14-dependent lipid signaling includes the conversion of membranous phosphatidylcholine $(\mathrm{PC})$ to diacylglcerol by PC-specific phospholipase C (PC-PLC) and the activation of sphingomyelinase (SMase) for sphingolipid metabolism and ceramide production. This process leads to the phosphorylation of protein kinase $\mathrm{C}(\mathrm{PKC}) \zeta$, which recruits TLR4 to interact with CD14 (Cuschieri et al. ${ }^{26}$ and Triantafilou et $\left.a{ }^{27}\right)$. Lipid messengers, such as sphingolipids and ceramides, and their downstream PKC $\zeta$ signals have been implicated in pro-apoptotic pathways and are considered tumor suppressors. ${ }^{28-30}$ Decreased SMase activity and $\mathrm{PKC} \zeta$ levels have been observed in human colorectal tumors, correlated with poor prognosis. ${ }^{31,32}$ In contrast, the TLR4/ MyD88 and $I_{K} \mathrm{~B} / \mathrm{NF}_{\kappa} \mathrm{B}$ pathways are associated with antiapoptotic and hyperproliferative responses. ${ }^{5,33-35}$ Reduced colorectal tumor formation has been documented in TLR4 (-/-), MyD88 $(-/-)$, and epithelial-specific $I_{\kappa} B$ kinase $\beta$-deficient mice as compared with wild-type (WT) mice. 5,19,36 These findings led us to speculate that the expression of CD14 and TLR4 on epithelial cell surfaces may provide antagonistic signals to counteract apoptotic responses to LPS and to influence tumor progression.

The aims of this study were to (1) investigate the expression patterns of LPS receptor subunits in normal and cancerous colonic epithelia in human and murine tissues; (2) examine the individual roles of CD14 and TLR4 in epithelial apoptosis and tumor formation using a mouse model of colitis-associated CRC; (3) assess the involvement of CD14-mediated lipid messengers and/or TLR4-dependent signaling in the mechanism of LPS-induced apoptosis using human carcinoma cell lines; and (4) evaluate whether TLR4 has an opposing role against CD14-mediated apoptosis to promote tumor cell survival.

\section{Results}

Human normal colonocytes express CD14 constitutively in the absence of TLR4, whereas cancerous cells display increased CD14 and TLR4 proteins. Surgical specimens from CRC patients were examined for the expression of LPS receptor subunits. Immunoreactivity on epithelial layers of morphologically normal regions was found positive to CD14 but negative to TLR4 or MD2 (Figure 1a), indicating that
CD14 was the only receptor subunit constitutively expressed in normal colonocytes. In cancerous tissues, increased epithelial expression levels of CD14 and TLR4 were observed without a change in MD2 levels (Figure 1a). The expression levels of CD14 and TLR4 were quantified in normal epithelium and tumorous regions (Figures $1 \mathrm{~b}$ and $\mathrm{c}$ ).

Augmentation of LPS-induced epithelial apoptosis correlates with a reduction of colonic tumorigenesis in TLR4-mutant mice. A colitis-associated CRC mouse model administered three cycles of azoxymethane/dextran sulfate sodium (AOM/DSS) was used to examine the relationship between epithelial cell death and tumor development, and the extent of LPS exposure to gut mucosa during disease progression. First, baseline levels of CD14/TLR4/MD2 were determined in mouse colonocytes isolated from untreated $\mathrm{BALB} / \mathrm{c}$ mice. Mouse colonocytes showed transcripts of the three receptor subunits (CD14, TLR4, and MD2) constitutively, and expressed CD14 and TLR4 proteins on the apical membrane of the surface epithelia and MD2 on the crypt epithelia (Figures $2 a$ and $b$ ). These results indicate that epithelial LPS receptor expression patterns differ between mice $\left(\mathrm{CD} 14^{+} \mathrm{TLR}^{+}\right)$and humans $\left(\mathrm{CD} 14^{+} \mathrm{TLR}^{-}\right)$at steadystate conditions. To mimic the absence of TLR4 in normal human colonocytes, genetically deficient mice and their WT counterparts were used for mutagen administration.

WT BALB/c mice, which are known high responders to AOM mutagen exposure, ${ }^{37,38}$ and TLR4-deficient mice harboring a spontaneous point mutation in the T/r4 gene at Pro712His (TLR4-mut mice; C.C3-TIr4 ${ }^{\text {LPS-d } / J ~ m o u s e ~ s t r a i n ~ w i t h ~ B A L B / c ~}$ background) were administered AOM/DSS. Mice were killed before (day 0 ) and 11, 25, 39, 68, and 80 days after the start of the first AOM injection, to examine the progression of tumorigenesis (Figure 3a). The genetic alteration and signaling dysfunctions were verified in TLR4-mut mice (Supplementary Figure S1). Multiple colonic tumors were observed (mainly distal colons) of WT mice with an incidence of $100 \%$ at late stages (i.e., 63 and 80 days) (Figures $3 b$ and c). Dysplastic features and high Ki-67 staining (a proliferation marker) were noted in the tumors of WT mice (Figures $3 d$ and e). The tumors of WT mice on 80 days mostly exhibited high-grade dysplasia to carcinoma. Moreover, the expression levels of CD14, TLR4, and MD2 were higher in tumorous tissues than in adjacent non-tumor tissues or in untreated (baseline) tissues (Figure 2b).

In contrast, 0 and $90 \%$ of TLR4-mut mice had colorectal tumors after 63 and 80 days, respectively. The tumor multiplicity and mean tumor area were significantly lower in TLR4-mut mice compared with WT mice (Figure 3c). The tumors in TLR4-mut mice on 80 days displayed low- to highgrade dysplasia. Using a method of apoptotic terminal deoxynucleotidyl transferase dUTP-biotin nick end labeling (TUNEL), we observed higher numbers of TUNEL-positive cells per area of tumor in TLR4-mut mice than in WT mice (Figure 3f). At early time points (i.e., 0, 11, 25, and 39 days), increased mucosal cell apoptosis was observed in TLR4-mut mice but not in WT mice (Figures $3 g$ and $h$ ). Mucosal cell proliferation levels, measured by immunoblotting for proliferating cell nuclear antigen, did not differ between WT and TLR4mut mice at early times (Figure $3 \mathrm{~h}$ ). These results suggest that 
a
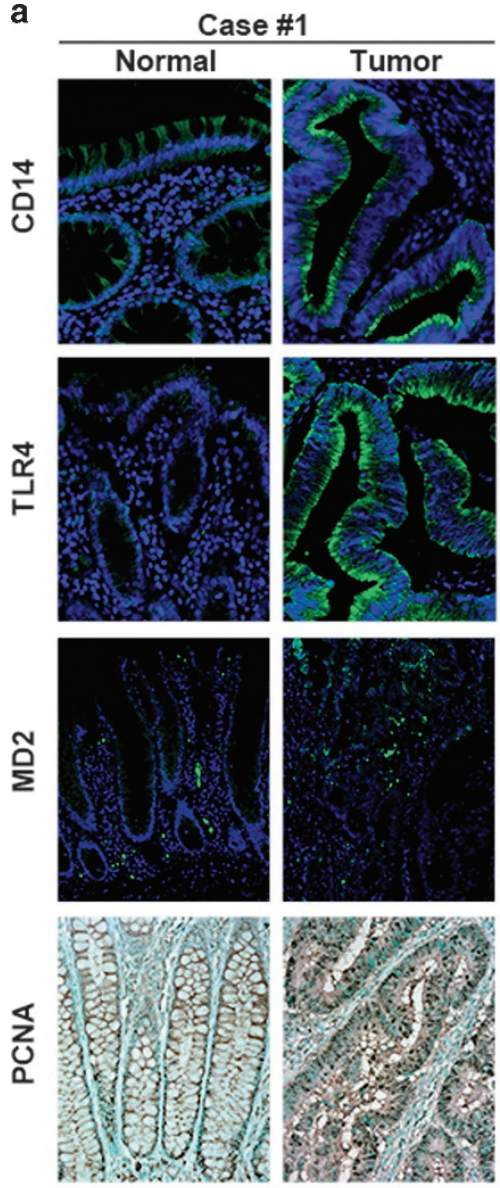


b

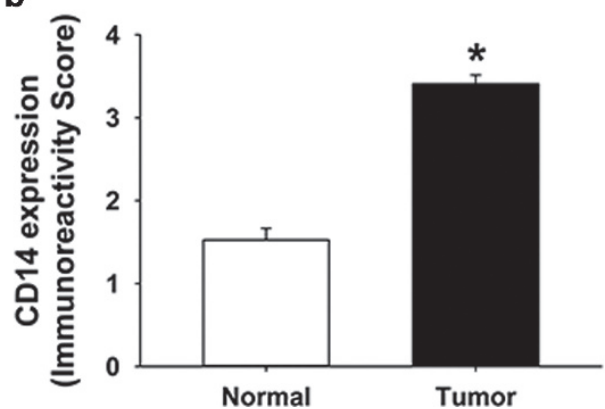

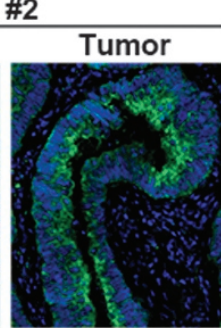
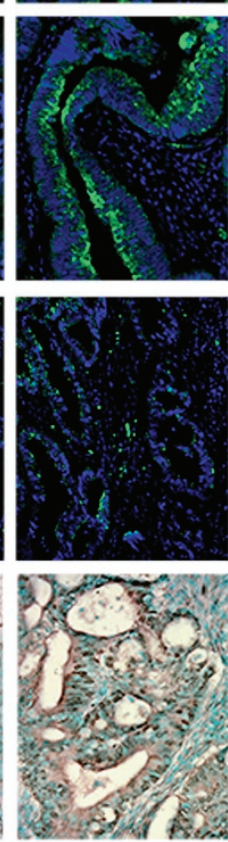
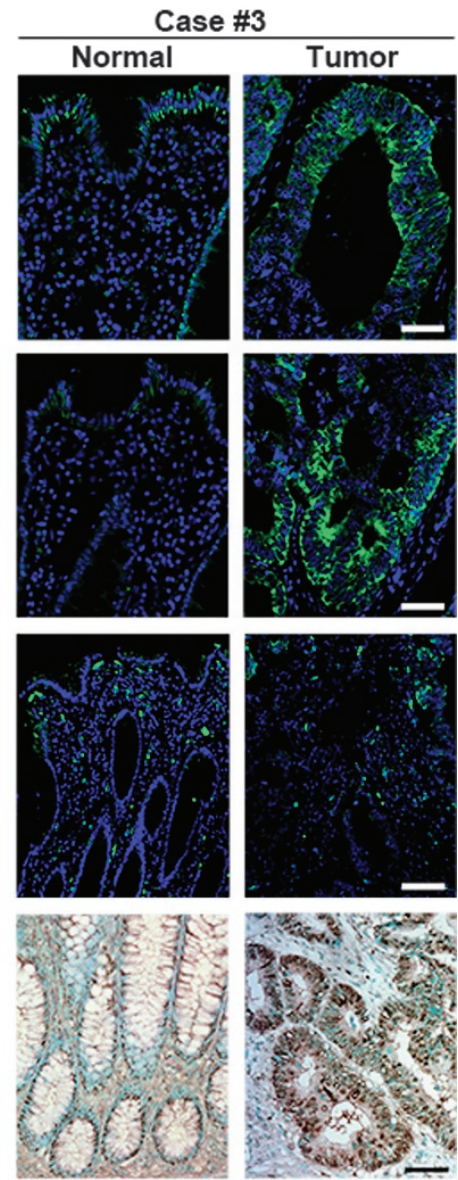

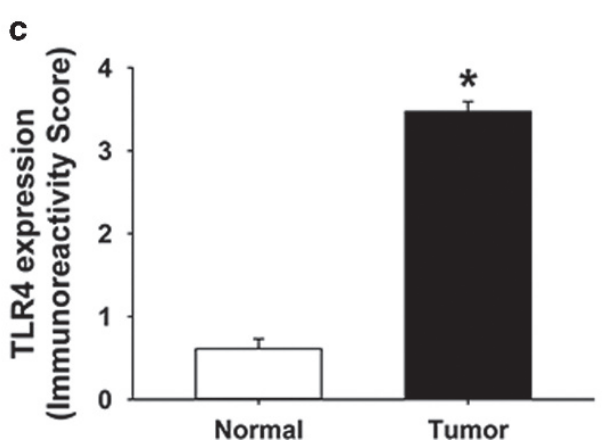

Figure 1 Human colonocytes in normal tissues express CD14 constitutively in the absence of TLR4, whereas cancerous tissues display enhanced levels of CD14 and TLR4. (a) Representative images of human surgical specimens of colonic adenocarcinoma from three clinical cases examined for the expression of LPS receptors. Fluorescent images indicate immunoreactivity to CD14, TLR4, or MD2 (green) superimposed with nuclear staining (blue). Apical expression of CD14 and the absence of TLR4 and MD2 were found on epithelial cells of morphologically normal tissues. Increased CD14 and TLR4 levels were observed in tumorous regions with no change in MD2 patterns. The levels of proliferating cell nuclear antigen (PCNA) in colonic tissues are in brown. Scale bar: $50 \mu \mathrm{m}$. (b and c) Immunoreactivity score of CD14 and TLR4 expression in normal epithelium and tumorous regions from thirty specimens. ${ }^{*} P<0.05$ versus normal

colonocytes are prone to apoptosis and are less susceptible to tumorigenesis in the absence of TLR4 signaling.

Intracolonic blockade of TLR4 reduced tumor growth in WT mice. A TLR4 antagonist eritoran ${ }^{39,40}$ was intracolonically administered to WT mice, to examine its effect on epithelial apoptosis and tumorigenesis. Mice were given eritoran or vehicle at different time points following CRC induction (Figure 4a). Significantly decreased tumor multiplicity and area were observed in mice with preventive and treatment regimen (Figures $4 \mathrm{~b}$ and $\mathrm{d}$ ). Tumor reduction correlated with enhanced apoptosis in cancerous tissues of mice administered eritoran, compared with those given vehicle (Figures $4 \mathrm{c}$ and $\mathrm{e}$ ).

Increased sensitivity to bacterial LPS triggers colonic epithelial apoptosis in a CD14-dependent manner. Mucosa-associated LPS levels in colonic tissues were 
elevated following AOM/DSS induction in WT and TLR4-mut mice, irrespective of mouse strain (Figure 3i). To examine whether DSS alone could increase mucosal LPS binding, mice were given DSS in drinking water without AOM injection. DSS challenge increased colonic mucosa-associated LPS content in both WT and TLR4-mut mice (Figure 3i), but only TLR4-mut mice displayed elevated mucosal apoptosis (Figure $3 \mathrm{~g}$ ). As low-dose (2-2.5\%) DSS was not toxic to epithelial cells in vitro, 5,41 and DSS alone did not increase mucosal apoptosis in WT mice (Figures $3 \mathrm{~g}$ and $\mathrm{h}$ ), we reasoned that epithelial cell death observed in TLR4-mut mice could be caused by increased sensitivity to LPS secondary to DSS challenge.

To verify whether increased sensitivity to commensal microbes and bacterial LPS causes epithelial apoptosis, and to evaluate the involvement of CD14 in the apoptotic response, mouse colons were subjected to non-ischemic loop ligation for the induction of commensal overgrowth (CO) in vivo or were mounted on tissue baths for LPS challenge from the mucosal side ex vivo. In the in vivo model, elevated mucosal apoptosis was detected only in TLR4-mut, but not WT, mice after induction of $\mathrm{CO}$ (Figure 5a). Increased gut-associated bacterial counts and mucosa-associated LPS levels were confirmed in both WT and TLR4-mut mice following loop ligation (Figures 5b and c).
In the ex vivo setting, colonic tissues obtained from untreated mice were LPS-challenged from the mucosal side. Augmented epithelial apoptosis was observed in TLR4-mut, but not WT, tissues (Figures $5 d$ and e). The LPS-induced epithelial apoptotic response was also seen in $\operatorname{TLR} 4(-/-)$ mouse tissues, but not in CD14( - / - ) mouse tissues or their WT counterparts (Supplementary Figure S2). To examine the involvement of epithelial CD14 in the apoptotic response, neutralizing anti-CD14 were administered intracolonically before LPS challenge in TLR4-mut mice. A significant reduction in the mucosal cell death level was observed in tissues pretreated with anti-CD14 compared with isotype antibody (Figure 5f). Anti-CD14 binding to epithelial surfaces was confirmed by immunostaining (Figure $5 \mathrm{~g}$ ).

LPS/CD14-induced epithelial apoptosis was prevented by TLR4 in primary colonic organoids derived from WT mouse crypts. Primary cultures of colonic organoids derived from mouse crypts were also developed for assessment of receptor expression and death response to LPS (Figure 6a). The presence of CD14, TLR4, and MD2 transcripts were identified along with Lgr5 (a marker of stem cells) in colonic organoids (Figure 6b). No sign of apoptosis was found after LPS challenge in WT colonic organoids; gene silencing of TLR4 but not CD14 increased the level of cell death (Figure 6c). In contrast, LPS-induced apoptosis was

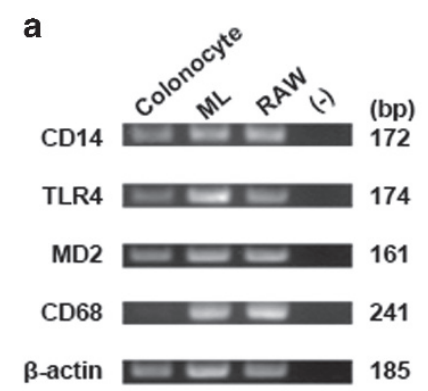

b
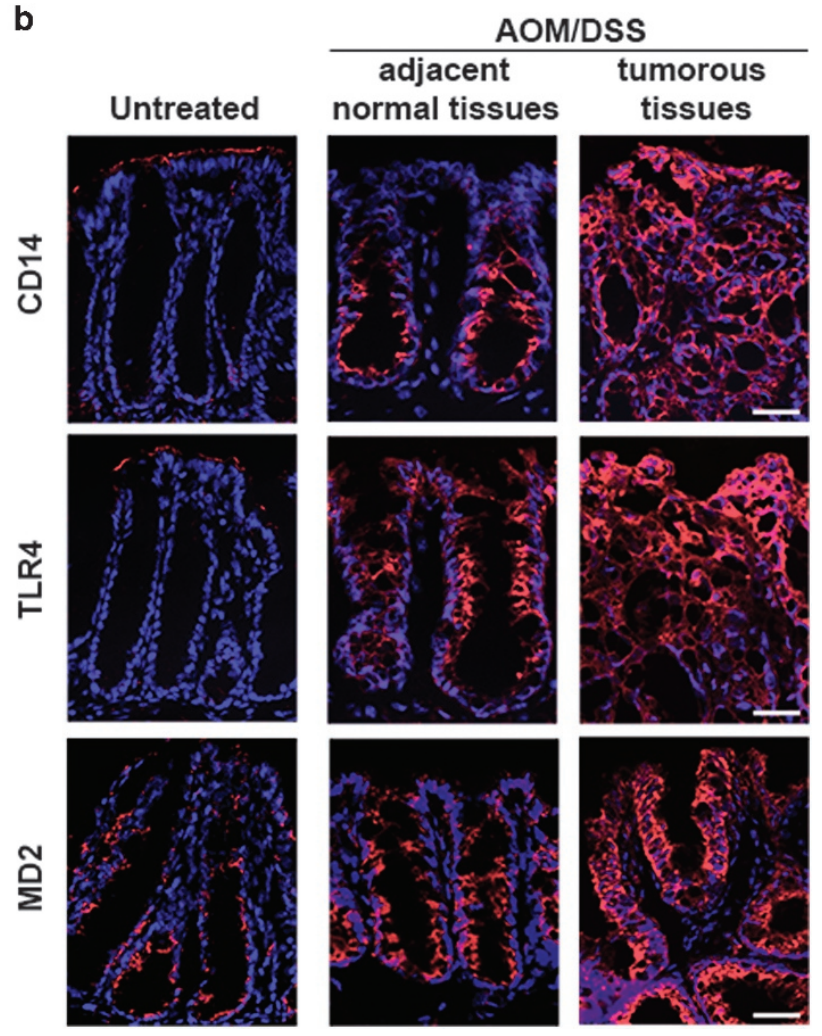

Figure 2 Baseline levels of CD14/TLR4/MD2 in mouse colonocytes and modification of expression levels in tumorous tissues. (a) Transcript levels of CD14, TLR4, and MD2 in mouse colonocyte cell preparations, showing the absence of CD68 transcripts (a marker of monocytes/macrophages). Mononuclear leukocytes (ML) and monocytic RAW264.7 (RAW) cells were used as positive controls for CD68. (b) Representative images of immunofluorescent staining of CD14, TLR4, or MD2 (red) in mouse colonic tissues, superimposed with nuclear staining (blue) for visual orientation. CD14 and TLR4 were localized to the apical membrane of the surface epithelium in untreated mouse colonic tissues, whereas MD2 was found on the crypt epithelium. Following three cycles of AOM/DSS, enhanced levels of CD14, TLR4, and MD2 were seen in tumorous tissues compared with adjacent normal tissues or untreated tissues. Scale bar: $50 \mu \mathrm{m} . n=10 /$ group 


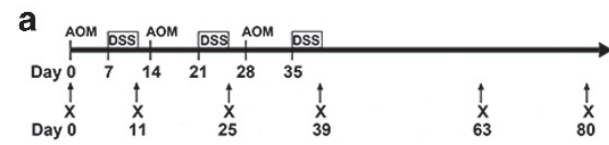

b
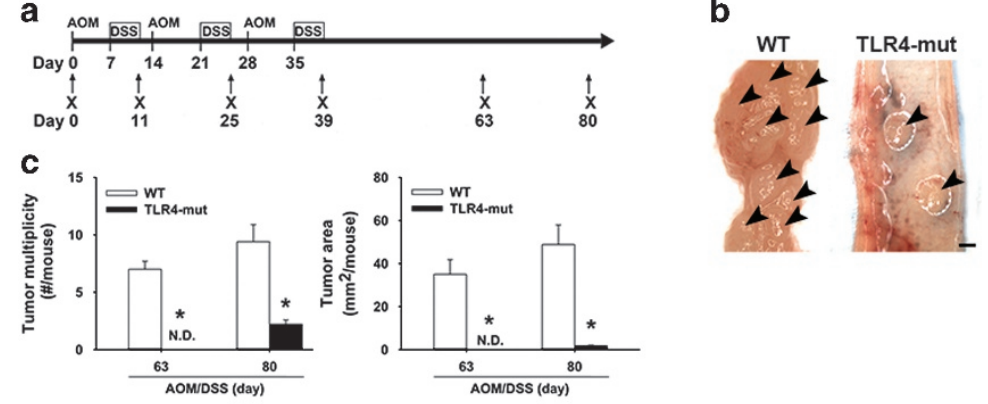

d

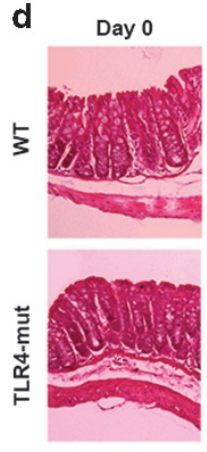

11

25
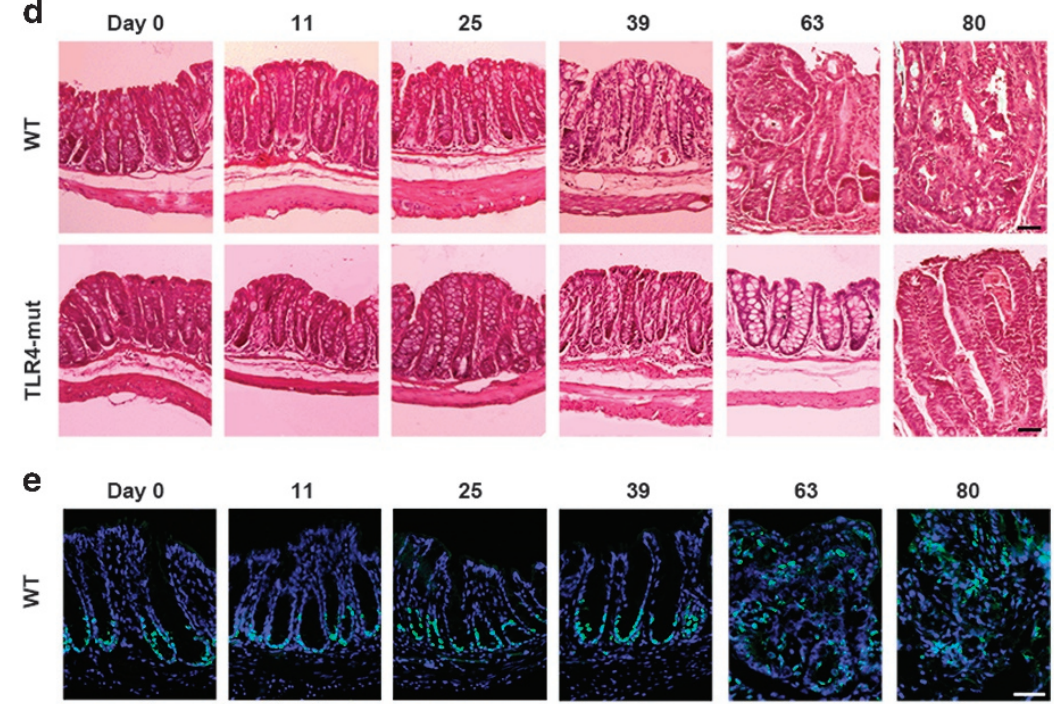

25
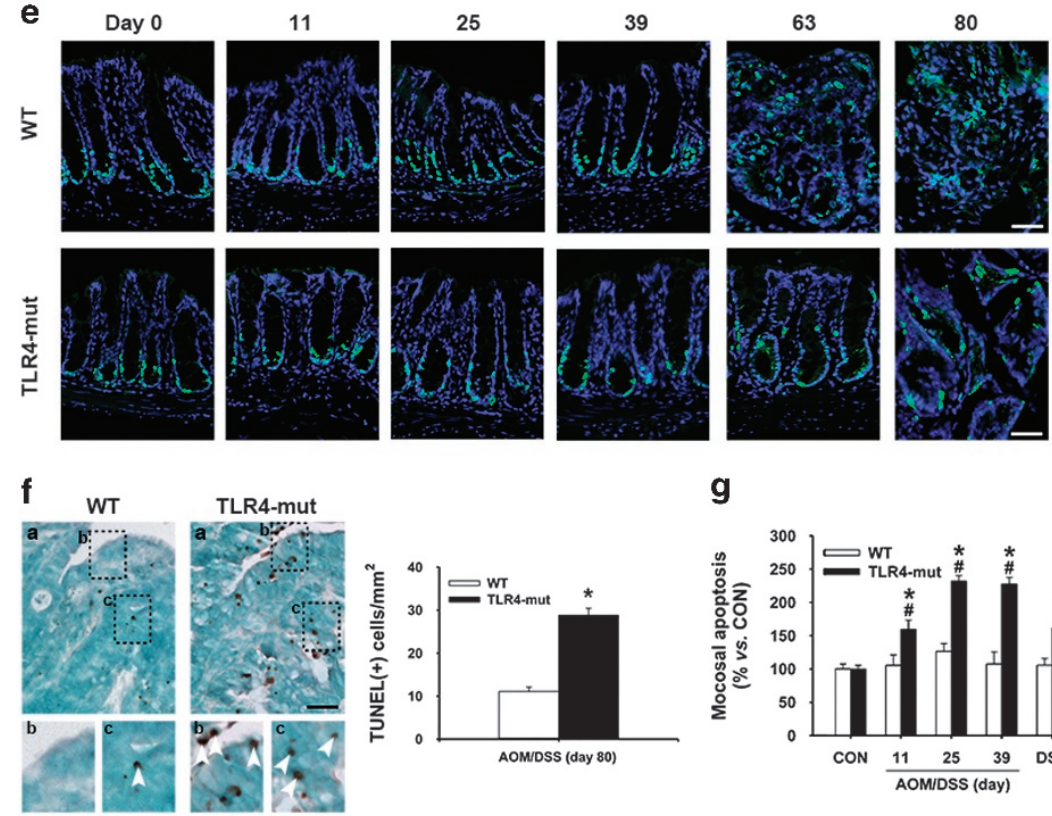

g

h
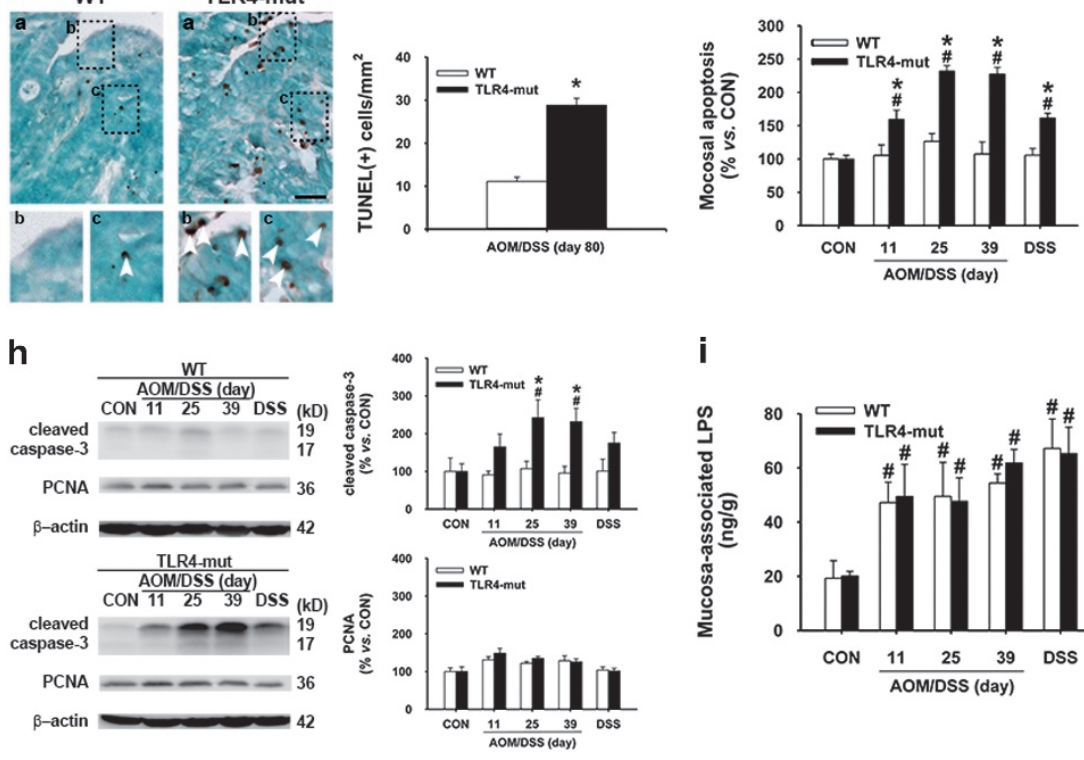

i

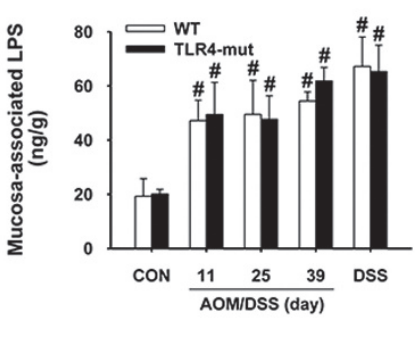


observed in TLR4-mut colonic organoids, which was inhibited by CD14 knockdown (Figure 6d). The knockdown efficiency in organoid cultures was confirmed by decreased transcript levels (Figures $6 \mathrm{c}$ and $\mathrm{d}$ ).

Exposure to LPS increases apoptosis in Caco-2 cells $\left(\right.$ CD14 $^{+}$TLR4 $^{-}$) but not in HT29 cells (CD14 ${ }^{+}$TLR4 ${ }^{+}$). Human CRC cell lines, that is, Caco-2, T84, and HT29, were used to investigate the molecular mechanism underlying LPS-induced apoptosis. Constitutive levels of CD14 transcripts and negligible amounts of TLR4 and MD2 were identified in Caco-2 cells (Figure 7A), whereas all three subunit transcripts were observed in T84 and HT29 cells (Figure 7A). Punctate apical CD14 staining was observed on Caco-2 and HT29 cells but not on T84 cells (Figure 7B).
TLR4 immunoreactivity was observed on the apical membranes of T84 and HT29 cells but not on Caco-2 cells (Figure 7B). The mRNA and protein levels of CD14, TLR4, and MD2 were not altered after LPS challenge in any of the cell lines (Figures 7A and $B$ ). The expression patterns of Caco-2 cells $\left(\mathrm{CD} 14^{+} \mathrm{TLR}^{-}\right)$resemble those of normal colonocytes, whereas HT29 cells $\left(\mathrm{CD} 14^{+} \mathrm{TLR}^{+}\right.$) resemble human cancerous tissues.

Death and survival responses to LPS challenge were assessed in the three cell lines. Caco-2 cells exposed apically to $\operatorname{LPS}(0,5,25$, and $50 \mu \mathrm{g} / \mathrm{ml})$ for $24 \mathrm{~h}$ showed increased DNA fragmentation and caspase-3 activation in a dose-dependent manner (Figures 7C and D). No indications of cell apoptosis were observed in LPS-challenged T84 or HT29 cells (Figures 7E and F). In Caco-2 cells, pretreatment with the caspase-3
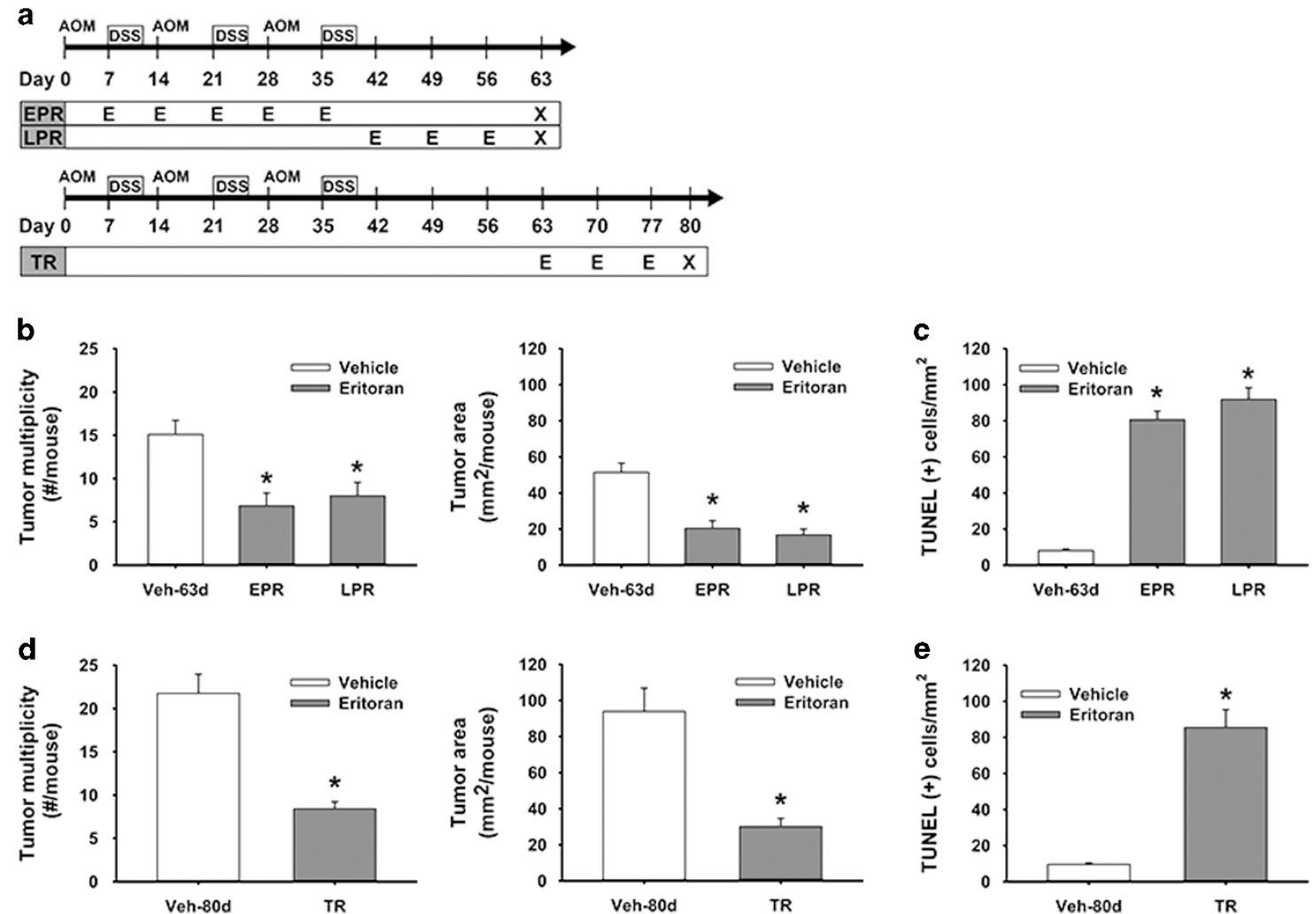

Figure 4 Decreased tumor growth was observed in WT mice intracolonically administered a TLR4 antagonist. Eritoran or vehicle (veh) was intracolonically given to WT mice at various time points, to evaluate its effect on CRC development. (a) Schema of early and late preventive regimen (EPR and LPR) and treatment regimen (TR). E, days administered eritoran; $X$, days for killing. (b and $\mathbf{c}$ ) Tumor multiplicity and area per mouse, and number of apoptotic cells per $\mathrm{mm}^{2}$ in tumors following preventive regimen. (d and $\mathbf{e}$ ) Tumor multiplicity and area per mouse, and number of apoptotic cells per $\mathrm{mm}^{2}$ in tumors following treatment regimen. $n=8-12 /$ group. ${ }^{*} P<0.05$ versus veh

Figure 3 A reduction in tumor formation correlates with increase of epithelial apoptosis in TLR4-mutant mice after administration of AOM/DSS. (a) Timeline of experimental design. WT and TLR4-mut mice were subjected to three cycles of AOM/DSS for the induction of colitis-associated CRC. Mice were killed before (day 0) and after the first AOM injection on day 11, 25, 39, 63, and 80. (b) Representative images of distal colons on day 80 . Arrowheads indicate tumors. Scale bar: 1 mm. (c) Tumor multiplicity and mean tumor area per mouse during late stages. N.D., non-detected. (d and e) Colonic histopathology and crypt cell proliferation levels were examined by hematoxylin and eosin staining, and by immunoreactivity to Ki-67 (green fluorescence) superimposed with Hoechst staining (blue fluorescence). Scale bar: $50 \mu \mathrm{m}$. (f) Number of apoptotic TUNEL-positive cells (arrowheads) per $\mathrm{mm}^{2}$ in colonic tumors obtained from mice on day 80 . Representative images of TUNEL staining (a) are shown at higher magnification (b and $\mathbf{c}$ ). Scale bar: $50 \mu \mathrm{m}$. (g) Mucosal cell apoptosis was quantified in untreated controls (CON), after AOM/DSS, or after DSS alone. (h) Western blot analysis showing mucosal levels of cleaved caspase-3 and proliferating cell nuclear antigen (PCNA) in untreated CON, after AOM/DSS, or after DSS alone. (i) Mucosa-associated LPS amounts in untreated CON, after AOM/DSS, or after DSS alone. $n=10$ /group. ${ }^{*} P<0.05$ versus $\mathrm{WT} ;{ }^{\#} P<0.05$ versus CON 
a

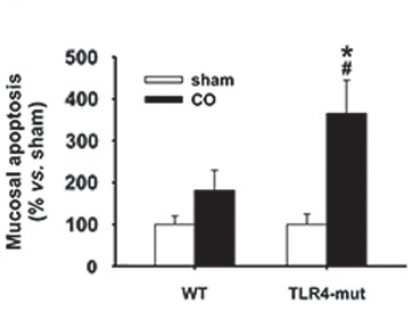

d

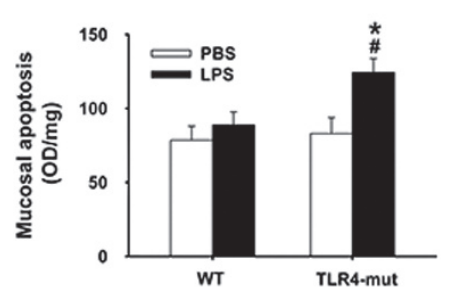

b

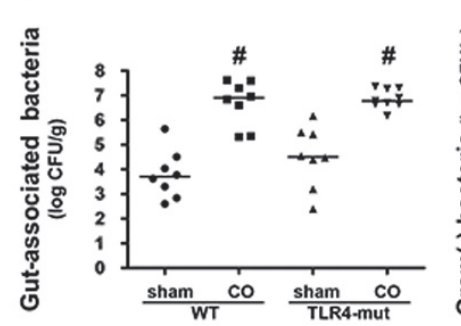

e

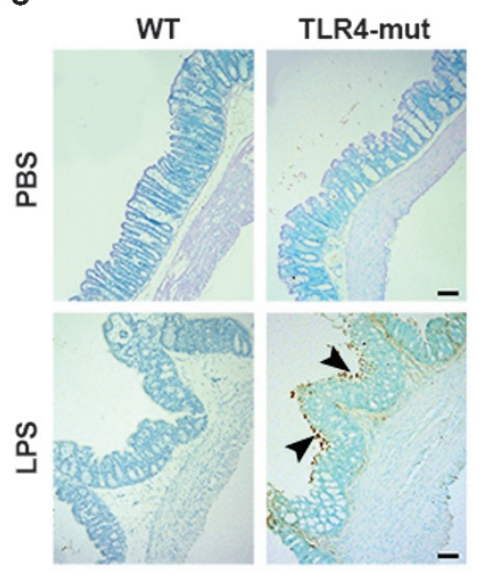

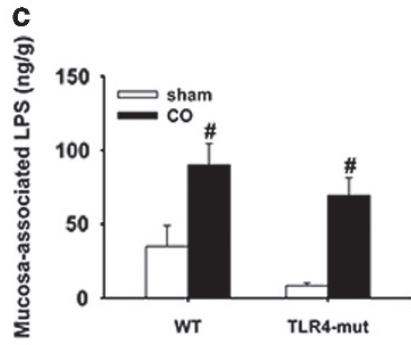

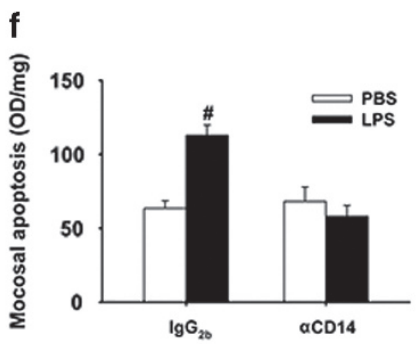

g

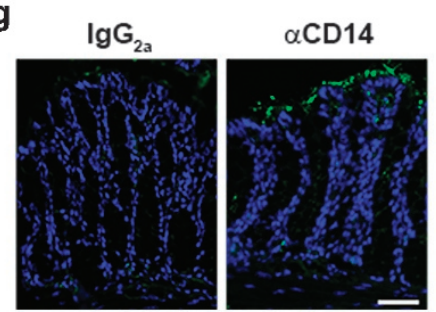

Figure 5 CD14-dependent epithelial apoptosis is augmented in colonic tissues of TLR4-mut mice after induction of CO or LPS challenge. WT and TLR4-mut mouse colons were subjected to non-ischemic loop ligation for induction of $\mathrm{CO}$ or were mounted on organ baths for LPS challenge from the mucosal side. (a) Augmented colonic mucosal apoptosis was detected in TLR4-mut but not WT mice after induction of CO. Sham-operated (sham) colons were without ligation. (b) Increased gut-associated and Gram-negative bacterial counts were confirmed after induction of CO in both WT and TLR4-mut mice. Each data point represents the bacterial count from one animal, and the median values are shown as bars. (c) Elevated mucosa-associated LPS levels were observed after $\mathrm{CO}$ in both mouse strains. (d) Colonic tissues obtained from untreated mice were challenged from the mucosal side with LPS or PBS, and increased mucosal apoptosis was seen in TLR4-mut mice compared with WT mice. (e) Apoptotic TUNEL-positive cells (arrowheads) were detected on the colonic epithelium after LPS challenge in TLR4-mut, but not WT, mice. Scale bar: $50 \mu \mathrm{m}$. (f) Intracolonic administration of neutralizing anti-CD14 antibody, but not its isotype lgG2b, decreased LPS-induced cell apoptosis. (g) Binding of anti-CD14 to epithelial surfaces was confirmed by immunofluorescent staining (green). Scale bar: $50 \mu \mathrm{m} . n=6$-8/group. ${ }^{*} P<0.05$ versus $\mathrm{WT}$; ${ }^{*} P<0.05$ versus sham or PBS

inhibitor, z-DEVD, blocked LPS-induced cell apoptosis and tight junction disruption (Supplementary Figure S3A-D). Inhibition of apoptosis with polymyxin B (PMB) treatment confirmed the specificity of the lipid A moiety of LPS as the death trigger (Supplementary Figure S3A-D).

\section{A mechanism of CD14-dependent lipid signaling without engaging TLR4 contributes to LPS-induced apoptosis.} To identify the LPS receptor subunits involved in cellular apoptosis, Caco-2 cells were treated with neutralizing antibodies or siRNAs before LPS challenge. Pretreatment with neutralizing anti-CD14 significantly reduced the numbers of apoptotic cells following LPS challenge, whereas antiTLR4 and isotype controls had no effect (Figures 8a and b). The LPS-mediated tight junction disruption was also attenuated by anti-CD14 but not by anti-TLR4 (Supplementary Figure S3E).

Gene silencing of CD14 decreased the LPS-induced apoptosis levels in Caco-2 cells (Figure 8c). The knockdown efficiency and specificity of siCD14 was confirmed by immunoblotting (Figure 8c). Increased PKC $\zeta$ phosphorylation following LPS challenge was attenuated by CD14 knockdown
(Figure 8d). Cells pretreated with inhibitors of PC-PLC, SMase, or $\mathrm{PKC} \zeta$, and cells that were $\mathrm{PKC} \zeta$ gene silenced, displayed reduction in apoptosis (Figures $8 \mathrm{c}$ and e). Moreover, ceramide (C16) synthesis and $\mathrm{PKC} \zeta$ activation were confirmed in cells after LPS challenge (Supplementary Figure S4), whereas no changes in phosphorylated MAPKs, IkB, Akt, and IRF3 levels were seen (Supplementary Figure S5).

LPS/CD14-mediated apoptosis can be overruled by functional TLR4 expression. We next examined whether functional TLR4 expression could serve as a pro-survival signal against apoptotic cell death caused by its coreceptor CD14. Caco-2 cells were transfected with either mock plasmids or a pMyc-CMV1-huTLR4 plasmid that encoded either WT or mutant TLR4 protein. Apical surface expression of TLR4 and Myc proteins was observed in pMyc-CMV1huTLR4-transfected cells, whereas mock-transfected cells were negative for TLR4 staining (Figures 9a and b). CD14 and MD2 protein levels remained constant in mock- and TLR4-transfected cells (Figure 9b). A reduction in LPSinduced cell apoptosis was observed after transfection with WT TLR4, but not after transfection with TLR4 
a
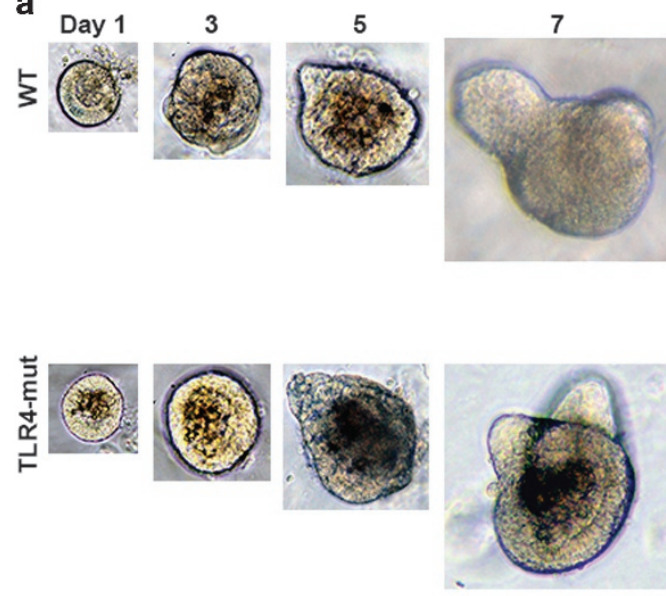

b

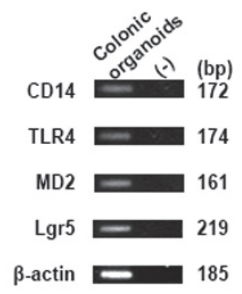

\section{2}

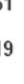

c

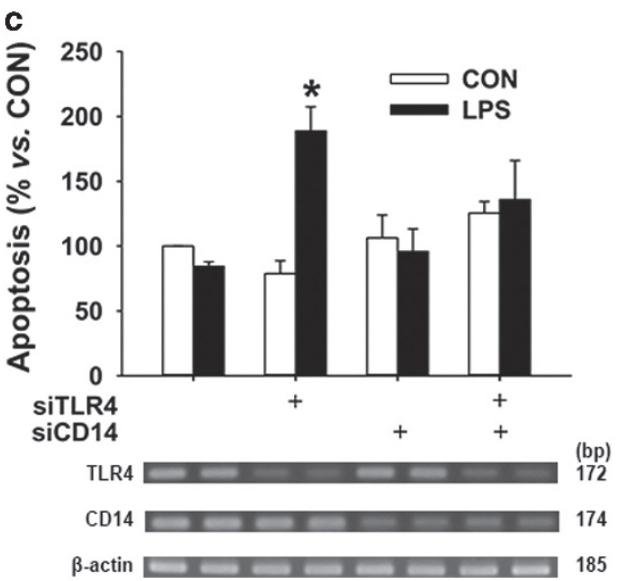

14
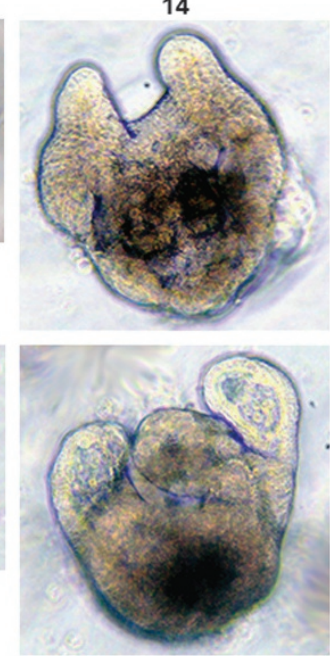
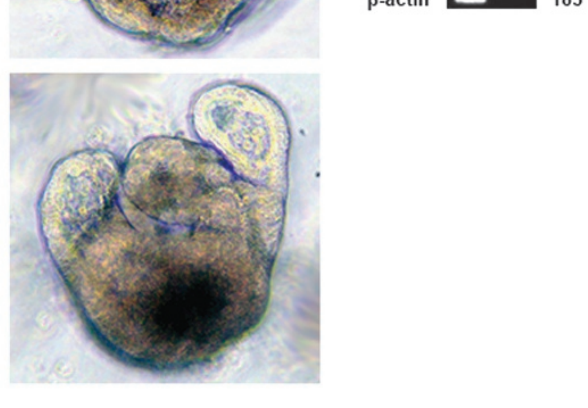

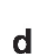

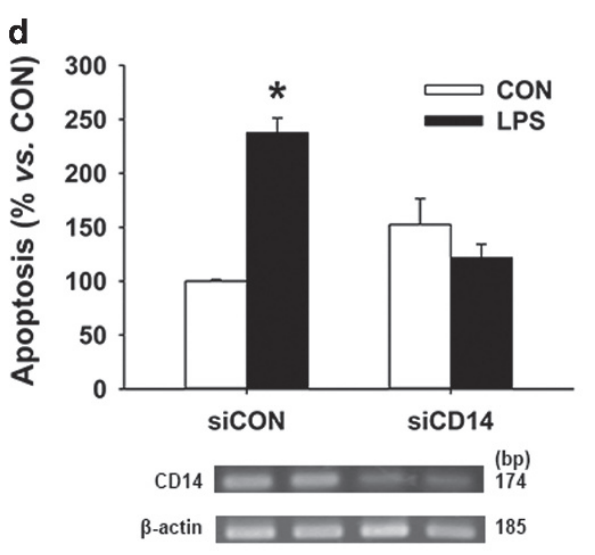

Figure 6 LPS/CD14-mediated epithelial apoptosis is prevented by TLR4 expression in primary mouse colonic organoids. (a) Representative images of colonic organoid cultures derived from colonic crypts of WT and TLR4-mut mice. Original magnification: $\times 200$. (b) Transcript levels of LPS receptors (CD14, TLR4, and MD2) and Lgr5 in WT colonic organoids. (c) Apoptotic levels by LPS challenge in WT colonic organoids with gene silencing of TLR4 and/or CD14. Organoids were either LPS challenged or untreated as controls (CON). (d) Apoptotic levels in TLR4-mut colonic organoids with gene silencing of $C D 14 . n=6$ /group. ${ }^{*} P<0.05$ versus respective CON

mutants (Asp299Gly, Thr399lle, and Pro714His) (Figure 9c). Each TLR4 mutant group exhibited dysfunctional signaling after LPS challenge, compared with WT TLR4, as evidenced by the phosphorylation status of JNK and IKB (Figure 9d). Moreover, spheroid cultures of Caco-2 cells showed a twofold increase in apoptotic levels following LPS challenge, which was ablated by knockdown of CD14 or overexpression of TLR4 (Figures 9e and f).

HT29 cells, which constitutively express TLR4 and CD14 proteins, were subjected to multiple gene knockdowns before LPS challenge for cell death responses. Immunoblottings indicated that single or double gene silencing approaches for TLR4, CD14, and/or PKC $\zeta$ were specific and did not alter proteins other than the target molecule(s) (Figure 9g). Knockdown of TLR4 resulted in loss of survival and increased apoptosis following LPS challenge, compared with mock cells. In contrast, silencing of CD14 or PKC $\zeta$ alone did not affect cell death levels (Figure 9h). Apoptotic levels of the double knockdowns, TLR4/CD14 or TLR4/PKC $\zeta$, were comparable to mock groups before and after exposure to LPS (Figure 9h).

\section{Discussion}

The present study aimed to dissect the individual roles of the LPS receptor subunits in the fundamental processes of cell death versus survival in the regulation of epithelial homeostasis and tumorigenesis. Our data showed that LPS/CD14mediated colonocytic apoptosis, in the absence of TLR4 signaling, was negatively associated with cancer progression (i.e., delayed onset and reduced number and size of tumors). LPS-induced epithelial apoptosis was dependent on CD14-mediated lipid messengers and $\mathrm{PKC} \zeta$ phosphorylation, and the cell death process could be overruled by TLR4 expression. This study is the first to describe a reciprocal functional antagonism between CD14 and TLR4, which serves to balance epithelial cell demise and survival. Our findings provide a new perspective for the evolution of innate immunity for janus-faced microbial regulation of gut homeostasis.

Different expression patterns of LPS receptor subunits were identified on normal human colonocytes $\left(\mathrm{CD} 14^{+} \mathrm{TLR}^{-}\right)$and 

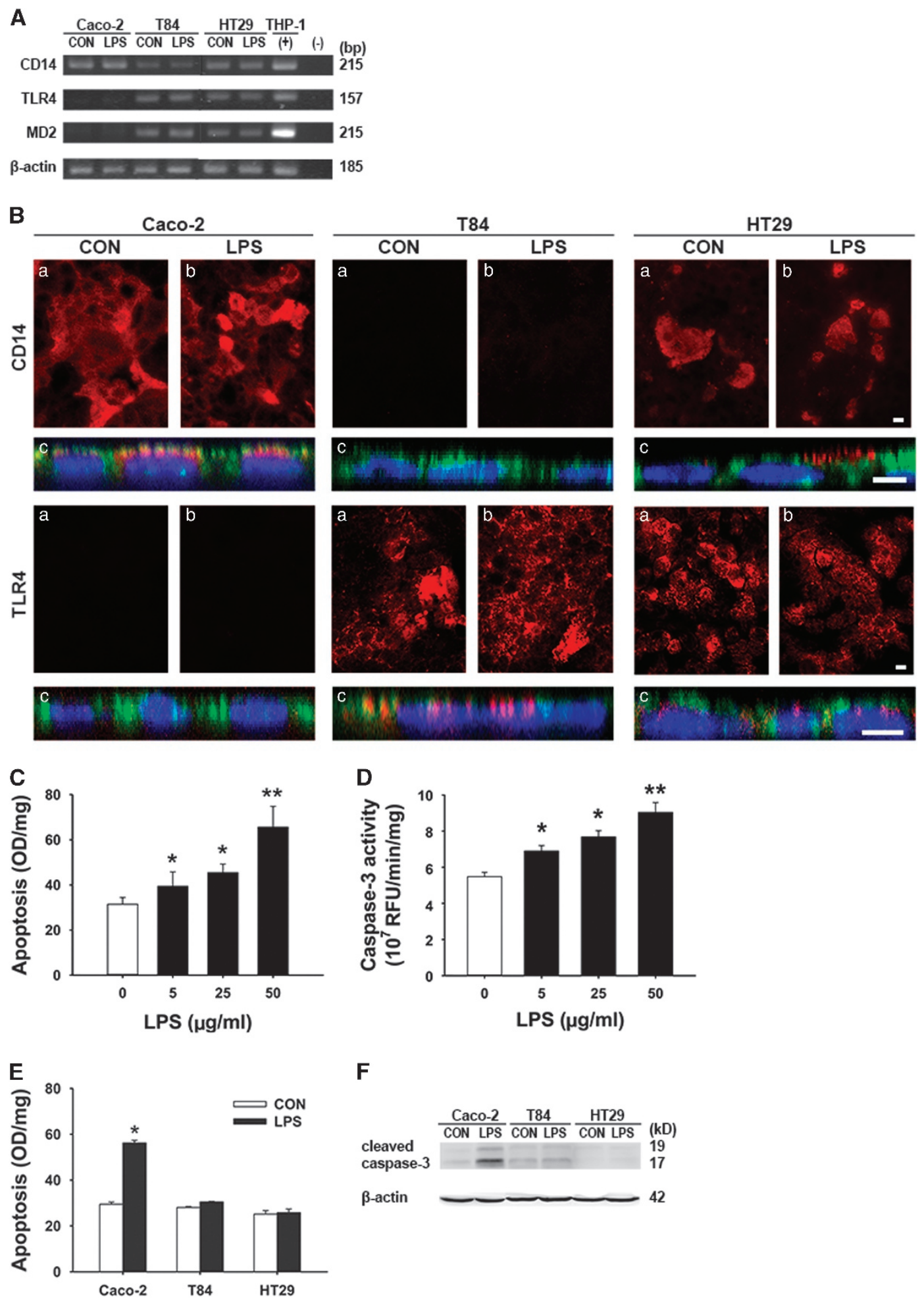

$\mathbf{F}$

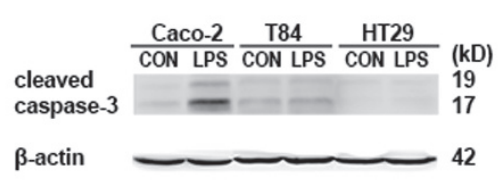

Figure 7 Apical exposure to LPS induces apoptosis in Caco-2 cells (CD14 $4^{+}$TLR4 $\left.{ }^{-}\right)$, but not in HT29 $\left(\mathrm{CD} 14^{+} \mathrm{TLR}^{+}\right)$or T84 (CD14-TLR4 $\left.{ }^{+}\right)$cells. The expression pattern of LPS receptors and death response to LPS were examined in three well-established human colorectal adenocarcinoma cell lines. (A) Levels of CD14, TLR4, and MD2 transcripts in control (CON) and LPS-challenged Caco-2, T84, and HT29 cells. Promonocytic THP-1 cells were used as positive controls. (B) Representative immunostaining of CD14 and TLR4 proteins in control (A and C) or LPS-exposed (B) cells. Confocal microscopic imaging in C indicates apical staining of CD14 or TLR4 (red) superimposed with nuclei (blue) and phalloidin-labeled F-actin (green). Scale bar: $5 \mu \mathrm{m}$. (C and D) Caco-2 cells were challenged with various doses of LPS for $24 \mathrm{~h}$ and displayed increased DNA fragmentation and caspase-3 activation in a dose-dependent manner. ${ }^{*} P<0.05$ and ${ }^{* *} P<0.005$ versus $0 \mu \mathrm{g} / \mathrm{ml}$ LPS. (E) LPS-induced apoptosis was observed in Caco-2 cells, but not in T84 or HT29 cells. ${ }^{*} P<0.05$ versus CON. (F) Western blots showing increased caspase-3 cleavage after LPS challenge in Caco-2 cells, but not in T84 or HT29 cells. Experiments were repeated at least twice. Scale bar: $5 \mu \mathrm{m} . n=4-6 /$ group 
a

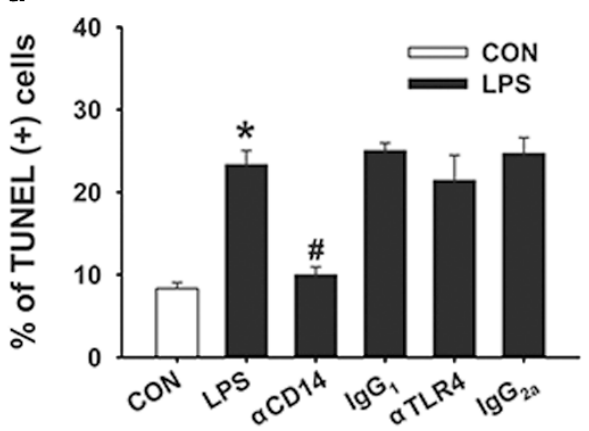

b

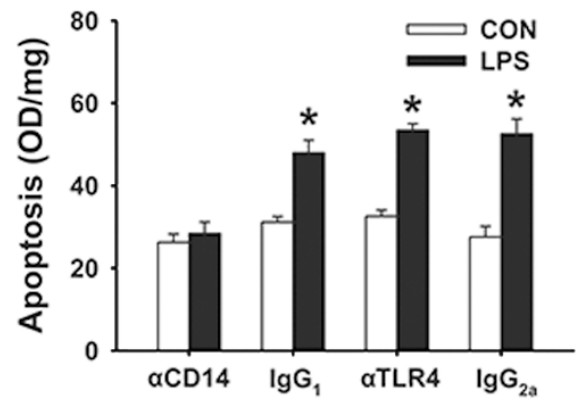

C
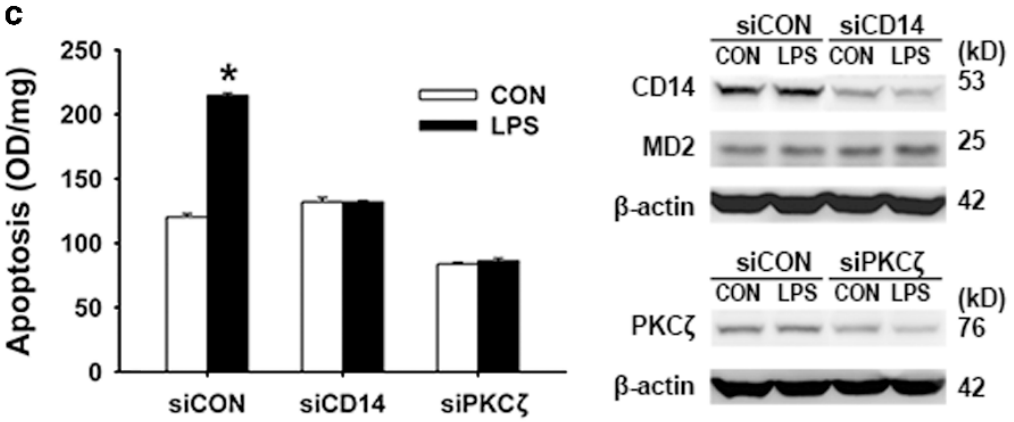

d



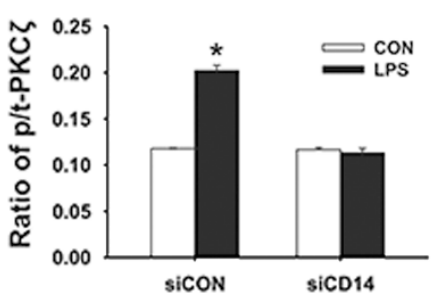

e

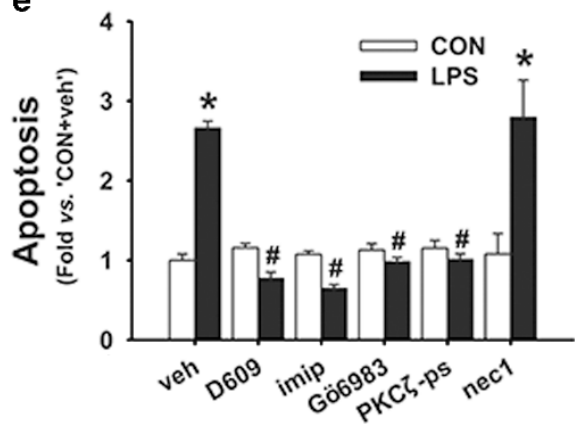

Figure 8 CD14-mediated lipid signaling is involved in LPS-induced apoptosis in Caco-2 cells. (a) Quantification of TUNEL-positive cells in control (CON) and LPS-challenged groups. The increase in the percentage of TUNEL-positive cells following LPS challenge could be inhibited with neutralizing anti-CD14 antibody, but not with anti-TLR4 or isotype antibodies. (b) LPS-induced apoptosis was inhibited by anti-CD14 but not anti-TLR4. (c) siRNA-mediated gene silencing of CD14 and PKC $\zeta$ prevented LPS-induced cell apoptosis. Western blotting confirmed the knockdown efficiency of CD14 and PKC $\zeta$, and indicated that MD2 levels were not affected by siRNA treatment. (d) Hyperphosphorylation of PKC $\zeta$, caused by LPS exposure, was reduced in CD14 knockdowns. Representative blots of total (t)- and phospho (p)-PKC $\zeta$ after CD14 knockdown. The p-PKC $\zeta$ to t-PKC $\zeta$ ratio was quantified by densitometric analysis. (e) Pretreatment with D609 (a PC-PLC inhibitor), imipramine (imip; a SMase inhibitor), Gö6983 (a PKC inhibitor), or PKC $\zeta$ pseudosubstrate (ps; a specific inhibitor of PKC $\zeta$ ) suppressed LPS-induced cell apoptosis. No effects were observed when vehicle (veh) or necrostatin-1 (nec1; a necroptosis inhibitor) were used. Experiments were repeated at least twice. ${ }^{*} P<0.05$ versus respective CON; ${ }^{\sharp} P<0.05$ versus LPS or LPS+veh. $n=4-6 /$ group

cancerous tissues (CD14 $\left.{ }^{+} \mathrm{TLR}^{+}\right)$. CD14 and TLR4 gene polymorphisms also have been correlated with a higher risk of CRC development, ${ }^{42-44}$ supporting a link between aberrant LPS recognition and cancer formation. Abundant studies demonstrated that TLR4/MyD88 signaling promotes colitis-associated CRC by causing cell hyperproliferation via cyclooxygenase-2, epidermal growth factor receptor, and $\beta$-catenin-dependent pathways. ${ }^{19,35,36,45,46}$ Mutated TLR4 also contributes to the epithelial-to-mesenchymal transition. ${ }^{43}$ Here we focused on the roles of LPS receptors on the dysregulation of epithelial death and survival responses for control of tumor progression. We demonstrated that in the absence of TLR4 signaling, colonocytes were prone to cell apoptosis and less susceptible to tumorigenesis, in keeping with previous findings of TLR4 $(-/-)$ and MyD88(-/-) mice. ${ }^{19,36}$ Based on the data of primary organoid cultures, colonocytic apoptosis triggered by LPS hypersensitivity was dependent on CD14 and could be prevented by epithelial TLR4 expression. Moreover, intracolonic administration of a TLR4 antagonist eritoran significantly enhanced cell apoptosis in tumors and reduced $C R C$ growth in WT mice, implicating therapeutic potential of the antagonist. Eritoran is a structural analog of the lipid A moiety of LPS that binds to the hydrophobic pocket of MD2 without causing its structural change necessary for dimerization of TLR4-MD2 complex and 
a

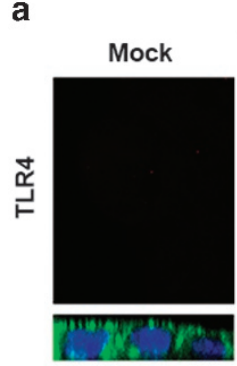



c
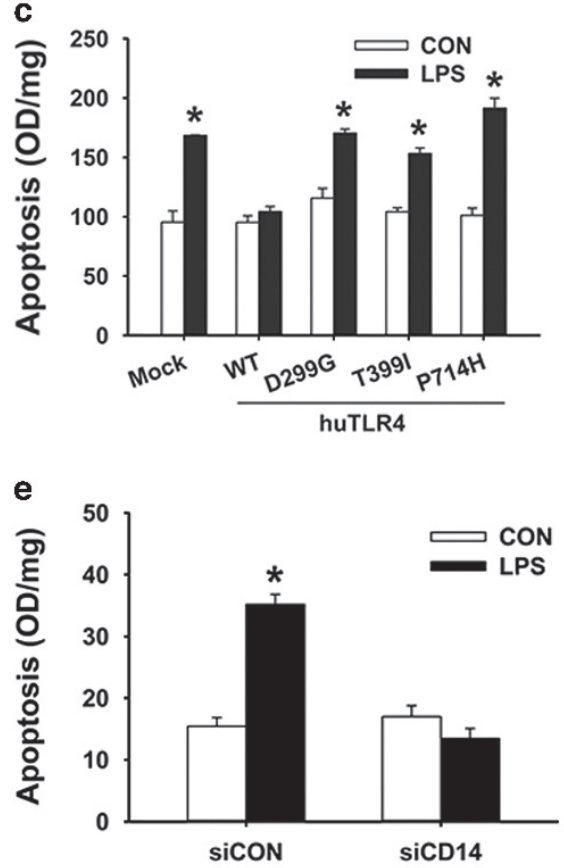

g

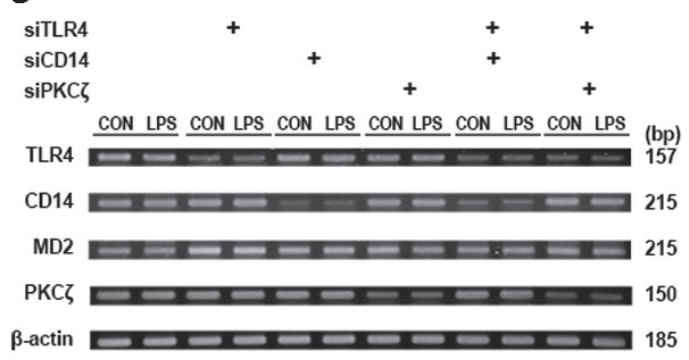

huTLR4

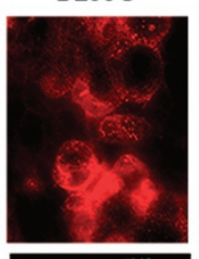

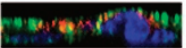

d

f

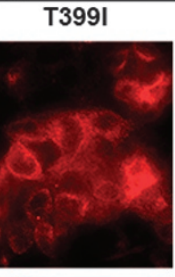

Totionation b

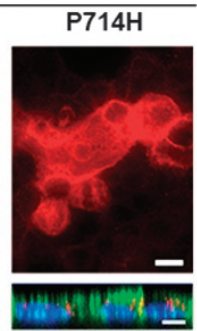

b Mock hUTLR4

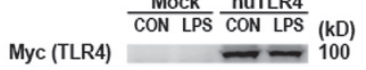

CD14 $=53$

MD2 --25

$\beta$-actin
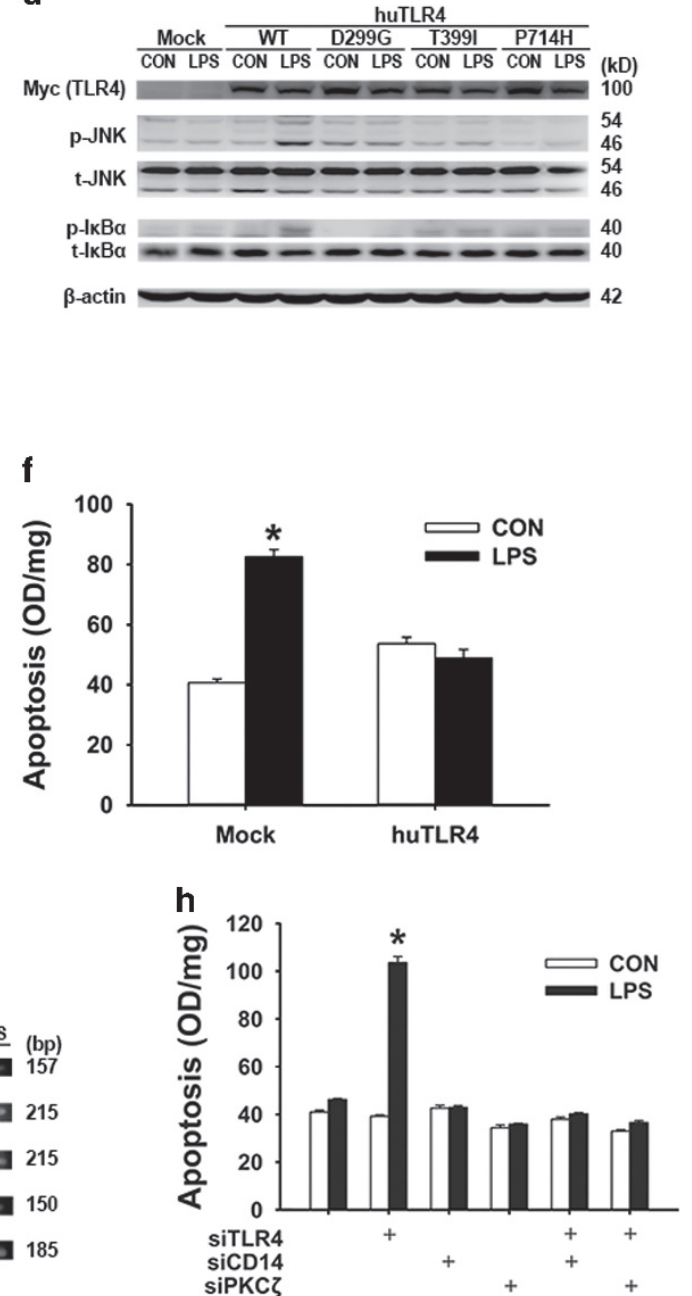

Figure 9 Expression of functional TLR4 inhibits LPS/CD14-induced apoptosis in Caco-2 cells. Caco-2 cells were transfected with mock plasmids or pMyc-huTLR4 expressing WT or mutant (Asp299Gly, Thr399lle, or Pro714His) TLR4 before LPS challenge. (a) Apical expression of TLR4 proteins in Caco-2 cells was verified after transfection. Representative en face views of TLR4 staining (red) are shown in the upper panels, and superimposed confocal images of TLR4 (red), F-actin (green), and nuclei (blue) are shown in the lower panels. Scale bar: $10 \mu \mathrm{m}$. (b) Representative blots of TLR4, CD14, and MD2 in transfected cells. Expression of TLR4 did not affect CD14 or MD2 levels in control (CON) or LPS-challenged cells. (c) LPS-induced apoptosis was abolished in cells transfected with pMyc-huTLR4 harboring the WT TLR4 insert, but not with mock plasmids. Site-directed mutagenesis of TLR4 proteins eliminated the anti-apoptotic effects in Caco-2 cells. (d) Functional TLR4 signaling, defined as LPS-induced JNK and IKB $\alpha$ phosphorylation, was observed in Caco-2 cells transfected with WT TLR4, but not in cells harboring mutated TLR4. (e and f) Spheroid cultures of Caco-2 cells showed increase of apoptosis following LPS challenge, which was ablated by knockdown of $C D 14$ or overexpression of TLR4. ${ }^{*} P<0.05$ versus respective CON. (g) HT29 cells underwent single or double knockdown of CD14, TLR4, or $P K C \zeta$, as verified by PCR. (h) LPS challenge induced elevated apoptosis in HT29 cells with TLR4 knockdown, whereas no change in apoptosis was observed in $\mathrm{CD} 14$ or $\mathrm{PKC} \zeta$ knockdowns or in double knockdowns. All experiments were repeated twice. ${ }^{*} P<0.05$ versus respective CON. $n=4 /$ group

downstream signaling. ${ }^{47}$ We suspect that tumor suppression by eritoran may be attributed to dual effects of TLR4 blocking and CD14 signaling. The opposing effects of CD14 and TLR4 on epithelial cell death and survival highlighted the indispensable roles of LPS receptor subunits in the regulation of tumorigenesis.

Oral DSS challenge may increase LPS exposure to gut mucosa, which could partially explain how low-dose DSS 
induces mild colitis. High (5\%), but not lower, concentrations of DSS are directly toxic to epithelial cells and may trigger severe inflammation. ${ }^{41}$ Conversely, exposure to $1-3 \%$ DSS (noncytotoxic doses) is associated with breakage of the epithelial barrier via unknown mechanisms. Our data and others have suggested that DSS, a polysaccharide, may modulate LPS binding on cell surfaces. Studies using monocytes and macrophages have reported that LPS binding through CD14 with the participation of scavenger receptor $A$ (without engaging TLR4) is largely responsible for LPS internalization and detoxification. ${ }^{25,48}$ The occupation of scavenger receptor A by DSS blocks LPS scavenging but enhances LPS signaling by increasing cell surface levels of CD14 and TLR4 (Czerkies et $a^{4}{ }^{48}$ ). Taken together, increased adherence and receptor binding of LPS to gut mucosa may explain the colitogenic effects of low-dose DSS.

We further investigated the molecular mechanism of LPS/ CD14-mediated colonocytic apoptosis in human epithelial cell cultures. In accordance with the expression patterns of LPS receptors, enhanced apoptotic death was observed in Caco-2 cells $\left(\mathrm{CD} 14^{+} \mathrm{TLR}^{-}\right)$, but not in HT29 cells $\left(\mathrm{CD} 14^{+} \mathrm{TLR}^{+}\right)$, following LPS challenge. Distinct protein and transcript expression patterns in CRC cell lines have been previously reported. ${ }^{49-51}$ The doses of LPS $(5-50 \mu \mathrm{g} / \mathrm{ml})$ required to evoke epithelial apoptosis exceeded the basal level documented in the luminal contents of rodent intestines $(\sim 1.8 \mu \mathrm{g} / \mathrm{ml})^{52}$ and the blood concentration reported to stimulate monocytic cytokine secretion or septic responses $(\sim 10 \mathrm{ng} / \mathrm{ml})$, suggesting that overgrowth or adherence of enteric bacteria may tip the balance from tolerance to cell death.

The apoptotic response required the activity of CD14dependent lipid messengers (e.g., ceramide production and PKC (phosphorylation) and the absence of TLR4 involvement. CD14-dependent TLR4-independent cell death also has been documented in terminally differentiated dendritic cells following exposure to high concentrations of LPS $(1-10 \mu \mathrm{g} / \mathrm{ml})$ as a means to regulate dendritic cell cycles. ${ }^{53}$ However, this report found that macrophages did not die after stimulation with highdose LPS and instead became refractory to further challenges via intracellular negative regulators to decrease TLR4 signaling. ${ }^{53,54}$ Another study demonstrated that macrophages undergo apoptosis after anthrax bacterium challenge in the presence of p38 or proteasome inhibition via TLR4/IRF-3 pathways. ${ }^{55}$ These findings suggest that LPS may trigger cell death response via different receptors on epithelial and immune cells that function as regulators of biological processes or as defensive and immune-evasive mechanisms.

Overexpression of functional TLR4 in epithelial cells overrules apoptotic responses triggered by its coreceptor, CD14. The pro-survival effects of TLR4 could be eliminated by sitedirected mutagenesis at Asp299Gly, Thr399lle, or Pro714His. These mutation sites correspond to the ligand-binding, coreceptor-binding, and signaling domains of TLR4, respectively. ${ }^{56}$ This indicates that the anti-apoptosis responses were dependent on signaling pathways downstream of TLR4 rather than on their interaction with CD14. Our animal experiments involving spontaneous mutation of TLR4 at Pro712His supported this notion. A characterization of TLRadaptor proteins and signaling pathways responsible for

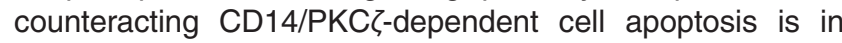

progress. The molecular cross-talk between CD14 and TLR4, and the role of MD2 in the antagonistic regulation of epithelial survival warrant further investigation.

In conclusion, we demonstrated that colonocytic apoptosis in response to bacterial LPS is mediated by CD14-dependent lipid messengers and may be counteracted by TLR4 signaling. Dysfunction in the CD14/TLR4 antagonism that regulates epithelial cell death and survival is correlated with tumor progression. The imbalances of CD14/TLR4 signaling may provide a working schema to explain the transition from normal cell turnover to carcinogenesis. Our data of tumor inhibition, partly via enhanced cell apoptosis, by intracolonic blockade of TLR4, highlighted a new direction for therapeutic intervention in human CRC.

\section{Materials and Methods}

Human colonic surgical specimens. Recruited subjects were patients referred for colonoscopy at National Taiwan University Hospital (NTUH). Thirty surgical specimens from the sigmoid colons of patients with $\mathrm{CRC}$ and respective normal mucosa were assessed. Written informed consent was obtained from all study subjects, and approval for this study was granted by the Research Ethics Committee of NTUH. Samples were fixed in $4 \%$ formaldehyde and paraffinembedded sections were used for immunostaining of CD14, TLR4, and MD2. The percentage of CD14- or TLR4-positive epithelial/tumor cells were scored on a scale of 0-4 (0: no staining; 1 : $\leq 10 \%$; 2: $11-30 \% ; 3: 31-50 \% ; 4:>50 \%$ ). ${ }^{57}$

Animals. WT mice (BALB/C and C57BL/6 strains), mice harboring a spontaneous mutation or knockout of the TLR4 gene (C.C3-T/r4 $4^{L P S-d / J}$ strain and B6.B10ScN-Trr4 ${ }^{L P S-d e l / J}$ strain, respectively), and CD14 gene knockout mice (B6.129S-Cd14 ${ }^{\text {tm1Frm } / J}$ strain), aged 7-10 weeks, were used in this study. WT mice were purchased from the animal facility at National Taiwan University College of Medicine. C.C3-T/r $4^{L P S-d} / J$ mice were provided by Dr John T Kung. B6.B10ScN$\mathrm{Tlr} 4^{L P S-d e l} / J$ mice were provided by Dr Fuu Sheu. B6.129 S-Cd14 ${ }^{\text {tm1 } 1 F r m} / J$ mice were purchased from Jackson Laboratory (Bar Harbor, ME, USA). All animals were raised in specific pathogen-free environments in temperature-controlled rooms $\left(23 \pm 2^{\circ} \mathrm{C}\right)$ with $12 \mathrm{~h}$ light-dark cycles. Experimental procedures were approved by the Laboratory Animal Care Committee of National Taiwan University College of Medicine.

Models of colitis-associated CRC. Mouse models of colitis-associated CRC were prepared according to previously established methods, with some modifications., ${ }^{5,19}$ Briefly, mice were injected intraperitoneally with AOM $(10 \mathrm{mg} / \mathrm{kg}$ body weight; Sigma, St Louis, MO, USA) at the beginning of the experiment (day 0). After 7 days, $2 \%$ DSS (MP Biomedicals, Santa Ana, CA, USA) was administered in the drinking water for 4 days, followed by 3 days of regular water. This cycle of AOM/DSS was performed three times. Body weight was measured every week and the animals were killed at the indicated time intervals for macroscopic inspection, histological analysis, and intestinal sample collection. Tumor numbers were determined macroscopically under an anatomic microscope and the tumor area measured using imaging software. Tissues were fixed in $4 \%$ paraformaldehyde (PFA) and paraffin-embedded for histological assessment by a gastrointestinal pathologist blinded to mouse genotype and treatment group. In a different setting, mice were given 2.5\% DSS in drinking water for 7 days and were killed for sample collection.

Tumor grading was classified as low-grade dysplasia, high-grade dysplasia, and carcinoma. Low-grade dysplasia indicates disorganized crypt structures associated with monolayered, hyperchromatic epithelial cells. High-grade dysplasia indicates disorganized crypt structures lined by stratified epithelial cells, back-to-back glands, high nuclear to cytoplasmic ratio, and loss of cellular polarity. Carcinoma was defined as loss of crypt architecture and penetration of the dysplastic region through basement membrane. ${ }^{58}$

Intracolonic administration of a TLR4 antagonist. ATLR4 antagonist eritoran tetrasodium (Eisai Inc., Andover, MA, USA) $)^{39,40}$ was administered intracolonically at various time points to WT mice following induction of CRC. Eritoran is a synthetic analog of lipid A structure of LPS. ${ }^{47}$ The dose of eritoran 
administered was $10 \mu \mathrm{g}$ dissolved in $150 \mu \mathrm{l}$ PBS per bolus per mouse. Mice were killed at either 63 or 80 days after starting the AOM/DSS procedure for examination of tumor growth.

Measurement of cell apoptosis. Scraped colonic mucosa were homogenized and sonicated in lysis buffer, and the supernatant was used for cell apoptosis assays. A cell death detection ELISA kit (Roche, Basel, Switzerland) that specifically measures the histone region of mono- and oligo-nucleosomes was used as an indicator of DNA fragmentation. ${ }^{20}$ In addition, a caspase-3 activity assay (Roche) was performed according to the manufacturer's instructions. Alternatively, tissues were fixed in 4\% PFA for TUNEL staining by using a DNA fragmentation detection kit (Merck, Darmstadt, Germany). The percentage of TUNEL-positive cells was calculated, normalized, and expressed per $1 \mathrm{~mm}^{2}$ from 10 tumor sections from each mouse group or per 100 epithelial cells in culture.

CO by intestinal loop ligation. Non-fasting mice underwent surgery for non-ischemic intestinal loop ligation to induce $\mathrm{CO}$. Briefly, mouse colons were mechanically obstructed with 4-0 nylon at both ends, to produce loop ligation, starting distal to the cecocolonic junction and ending proximal to the rectum. ${ }^{59}$ Sham-operated mice received laparotomy and mock manipulation of the gut without ligation. Animals were killed $24 \mathrm{~h}$ after surgery, and colonic tissues were collected for the measurement of gut-associated bacterial counts, mucosal LPS levels, and cell apoptosis. ${ }^{60}$

LPS challenge to mouse colonic tissues in ex vivo tissue baths. A $1-\mathrm{cm}$ segment of colon was excised and immediately placed in warmed Krebs buffer. Two pieces of colonic tissues from each mouse were cut longitudinally into flat sheets and mounted on Ussing chambers, exposing the luminal and serosal sides of the intestine (an area of $0.7 \mathrm{~cm}^{2}$ ) to $5 \mathrm{ml}$ of circulating oxygenated Krebs buffer at $37^{\circ} \mathrm{C}$. The serosal buffer contained $10 \mathrm{mM}$ of glucose as an energy source osmotically balanced with $10 \mathrm{mM}$ of mannitol in the luminal buffer. Based on the LPS concentration optimized in our previous studies, ${ }^{20,61}$ tissues were luminally challenged with LPS $(50 \mu \mathrm{g} / \mathrm{ml})$ or PBS for $2 \mathrm{~h}$, and then were removed for measurement of cell apoptosis. Bacterial LPS was derived from E. coli O26:B6 and was purchased from Sigma.

In another experimental setting, colonic tissues were pretreated with neutralizing antibody to CD14 (25 $\mu \mathrm{g} / \mathrm{ml}$, BD Biosciences, San Jose, CA, USA) or with IgG2b isotype controls before LPS challenge. Briefly, mice were fasted but allowed to drink water ad libitum, to ensure no luminal contents were left in the proximal colonic segment. After anesthetizing, mice underwent aseptic laparotomy and the proximal colon was ligated into a 3-cm loop into which antibodies in $0.25 \mathrm{ml}$ PBS were carefully administered using a 26-gauge needle with polyethylene tubing. After $30 \mathrm{~min}$, colonic tissues were excised and mounted in tissue baths for mucosal LPS challenge.

Intestinal organoid cultures. Mouse colonic crypt cells were cultured as organoids following previously described methods, ${ }^{62,63}$ with some modification. Briefly, cell clusters of the crypt fractions were isolated by using an EDTAdetachment method. After counting, around 1500 cell clusters were plated in $300 \mu \mathrm{l}$ ice-cold Matrigel (BD Biosciences, 356235) (3:1 ratio with crypt culture medium) per well of 24-well plates. After the polymerization of Matrigel, $300 \mu$ l of crypt culture medium was overlaid. The crypt culture media is composed of advanced Dulbeco's modified Eagle medium (DMEM)/F12 (Life Technologies, Carlsbad, CA, USA) supplemented with $100 \mathrm{ng} / \mathrm{ml}$ mouse recombinant Wnt3A (R\&D Systems, Minneapolis, MN, USA), $50 \mathrm{ng} / \mathrm{ml}$ epidermal growth factor (Life Technologies), $100 \mathrm{ng} / \mathrm{ml}$ Noggin (PeproTech, Rocky Hill, NJ, USA), $500 \mathrm{ng} / \mathrm{ml}$ R-spondin-1 (Peprotech), $1 \mu \mathrm{M}$ Jag-1 (AnaSpec, Fremont, CA, USA), $10 \mu \mathrm{M}$ Y-27632 (Sigma), $2 \mathrm{mM} \mathrm{L}$-glutamine, $100 \mathrm{U} / \mathrm{ml}$ penicillin, $100 \mu \mathrm{g} / \mathrm{ml}$ Streptomycin (Life Technologies), and $2 \%$ heat-inactivated fetal bovine serum (Biological Industries, Kibbutz Beit Haemek, Israel). The overlaying medium was refreshed every 2-3 days. The organoids were grown for up to 14 days, and images were captured under a light microscope. Organoids were collected by dissolving Matrigel with recovery solution (BD Biosciences). The transcript levels of CD14, TLR4, MD2, and Lgr5 were examined by reverse transcription-PCR (RT-PCR). Organoids grown for 5 days were challenged by adding LPS to the overlaying medium at a final concentration of $50 \mu \mathrm{g} / \mathrm{ml}$ for $24 \mathrm{~h}$, and collected for measurement of cell death.

In another setting, gene silencing by siRNA was conducted $48 \mathrm{~h}$ before LPS challenge in organoids. Organoids were transfected with $50 \mathrm{nM}$ of siRNA oligonucleotides from a pool of four target-specific 20-25 nt siRNAs that target CD14, TLR4, or scrambled controls (Santa Cruz, Dallas, TX, USA) using
Lipofectamine RNAiMAX Reagent (Life Technologies) in serum-free basal DMEM/ F12 medium for $6 \mathrm{~h}$. The basal medium was switched back to serum-containing complete medium for $48 \mathrm{~h}$, and organoids were then exposed to LPS for $24 \mathrm{~h}$. Knockdown efficiencies in the transfected cells were confirmed by RT-PCR.

LPS challenge in cell cultures. Human CRC Caco-2 and HT29 cells were grown in DMEM (Life Technologies). ${ }^{20,61,64}$ T84 cells were grown in DMEM/Nutrient Mixture F-12 Ham (DMEM/F-12) (Sigma). Cells were apically exposed to $50 \mu \mathrm{g} / \mathrm{ml}$ bacterial LPS (from E. coli O26:B6; Sigma) for $24 \mathrm{~h}$, unless stated otherwise, and were examined for apoptotic levels.

In some experiments, cells were pretreated with inhibitors or blocking antibodies 30 min before LPS challenge. These included $120 \mu \mathrm{M}$ Z-DEVD-FMK (z-DEVD, a caspase-3 inhibitor; Merck), $10 \mu \mathrm{g} / \mathrm{ml} \mathrm{PMB} \mathrm{(a} \mathrm{LPS} \mathrm{antagonist;} \mathrm{Sigma),} 50 \mu \mathrm{M}$ D609 (a PC-PLC inhibitor; Sigma), $5 \mu \mathrm{M}$ imipramine (a SMase inhibitor; Sigma), $60 \mathrm{nM}$ Gö6983 (a broad spectrum PKC inhibitor; Merck), $20 \mu \mathrm{M}$ inhibitory PKC $\zeta$ pseudosubstrate (Merck), $100 \mu \mathrm{M}$ necrostatin-1 (a necroptosis inhibitor; Sigma), $10 \mu \mathrm{g} / \mathrm{ml}$ neutralizing mouse anti-human CD14 (R\&D systems), $20 \mu \mathrm{g} / \mathrm{ml}$ neutralizing mouse anti-human TLR4 (eBioscience, San Diego, CA, USA), or their respective IgG1and lgG2a isotype controls. The topoisomerase-l inhibitor, camptothecin $(50 \mu \mathrm{M}$; Sigma), was used as a positive control for apoptosis after $24 \mathrm{~h}$ of incubation.

siRNA-mediated knockdown. Cells were transfected with $50 \mathrm{nM}$ of siRNA oligonucleotides targeting CD14, TLR4, or PKC $\zeta$ (Santa Cruz) using Lipofectamine RNAiMAX Reagent (Life Technologies) in serum-free basal medium. After $24 \mathrm{~h}$, cells were trypsinized and reseeded in culture plates at $0.5-1 \times 10^{6} \mathrm{cells} / \mathrm{well}$ for $48 \mathrm{~h}$ with complete medium before LPS challenge. Our pilot study indicated tight junctional formation $48 \mathrm{~h}$ after reseeding, as measured by transepithelial electrical resistance.

Plasmid constructs and point mutation. The expression vector pMycCMV1-huTLR4 was kindly provided by Dr Douglas T Golenbock (University of Massachusetts Medical School, Worcester, MA, USA). Point mutations for Asp299Gly, Thr399lle, or Pro714His were created by site-directed mutagenesis using KAPA HiFi PCR kits (Kapa Biosystems, Woburn, MA, USA), according to the manufacturer's instructions. Cells were transfected with pMyc-CMV1-huTLR4 plasmids ( $2.5 \mu \mathrm{g} /$ well each) before LPS challenge.

Statistical analysis. All data were expressed as mean \pm S.E.M., except that bacterial colony-forming units were presented as median values. When the normality assumption was appropriate, data were statistically analyzed by one-way ANOVA followed by the Student-Newman-Keuls post-hoc test for multiple comparisons. When comparing the differences between two groups of data that failed to satisfy the normality assumption, a non-parametric Mann-Whitney U-test was used. $P<0.05$ was considered statistically significant.

Detailed information regarding isolation of mouse intestinal epithelial cells and blood mononuclear leukocytes, histopathological examination, RT-PCR, histopathological examination, immunofluorescence staining and confocal microscopy, western blotting, enzyme-linked immunosorbent assay (ELISA), quantification of mucosaassociated LPS levels, cell lines, lipid extraction and ultra-performance liquid chromatography-tandem mass spectrometry, and plasmid constructs and point mutation are provided in the Supplementary Text.

\section{Conflict of Interest}

The authors declare no conflict of interest.

Acknowledgements. We thank the staff of the imaging and sequencing facility at the First Core Laboratory of National Taiwan University College of Medicine and the Disease Animal Research Center at the National Research Program for Biopharmaceuticals for technical assistance. This study was supported by grants from the National Science Council (NSC99-2320-B-002-024-MY3; NSC99-2628B-002-008-MY3; NSC102-2325-B-002-030; NSC102-2628-B-002-009-MY3) and National Taiwan University (102R39012).

\section{Author contributions}

Guarantor of integrity of the entire study, study concepts and design: LCY; data acquisition: WTK, TCL, HYY, CYC, YCA, YZL, LLW, YC, and YHT; data analysis/ interpretation: WTK, TCL, HYY, CYC, TCL, SCW, YHN, and LWL; statistical analysis: 
WTK and HYY; material and technical support: BRL, YC, YHT, JTK, and FS; obtained funding: LCY, SCW, and YHN; drafted manuscript or revised for important intellectual content, literature research, manuscript editing, and manuscript final version approval: all authors.

1. Hanahan D, Weinberg RA. Hallmarks of cancer: the next generation. Cell 2011; 144 646-674.

2. Bedi A, Pasricha PJ, Akhtar AJ, Barber JP, Bedi GC, Giardiello FM et al. Inhibition of apoptosis during development of colorectal cancer. Cancer Res 1995; 55: 1811-1816.

3. Miura K, Fujibuchi W, Ishida K, Naitoh T, Ogawa H, Ando T et al. Inhibitor of apoptosis protein family as diagnostic markers and therapeutic targets of colorectal cancer. Surg Today 2011; 41: 175-182.

4. Shanmugathasan M, Jothy S. Apoptosis, anoikis and their relevance to the pathobiology of colon cancer. Pathol Int 2000; 50: 273-279.

5. Greten FR, Eckmann L, Greten TF, Park JM, Li ZW, Egan LJ et al. IKKbeta links inflammation and tumorigenesis in a mouse model of colitis-associated cancer. Cell 2004; 118: 285-296.

6. Hu Y, Le Leu RK, Young GP. Absence of acute apoptotic response to genotoxic carcinogens in p53-deficient mice is associated with increased susceptibility to azoxymethane-induced colon tumours. Int J Cancer. 2005; 115: 561-567.

7. Duckworth CA, Pritchard DM. Suppression of apoptosis, crypt hyperplasia, and altered differentiation in the colonic epithelia of bak-null mice. Gastroenterology 2009; 136: 943-952.

8. Liu F, Bardhan K, Yang D, Thangaraju M, Ganapathy V, Waller JL et al. NF-kappaB directly regulates Fas transcription to modulate Fas-mediated apoptosis and tumor suppression. J Biol Chem 2012; 287: 25530-25540.

9. Yu LC, Wang JT, Wei SC, Ni YH. Host-microbial interactions and regulation of intestinal epithelial barrier function: from physiology to pathology. World J Gastrointest Pathophysiol 2012; 3: 27-43.

10. Edelblum KL, Yan F, Yamaoka T, Polk DB. Regulation of apoptosis during homeostasis and disease in the intestinal epithelium. Inflamm Bowel Dis 2006; 12: 413-424.

11. Shirkey TW, Siggers RH, Goldade BG, Marshall JK, Drew MD, Laarveld B et al. Effects of commensal bacteria on intestinal morphology and expression of proinflammatory cytokines in the gnotobiotic pig. Exp Biol Med (Maywood) 2006; 231: 1333-1345.

12. Rakoff-Nahoum S, Paglino J, Eslami-Varzaneh F, Edberg S, Medzhitov R. Recognition of commensal microflora by toll-like receptors is required for intestinal homeostasis. Cell 2004; 118: 229-241.

13. Scharl M, Rogler G. Microbial sensing by the intestinal epithelium in the pathogenesis of inflammatory bowel disease. Int J Inflamm 2010; 2010: 671258.

14. Rakoff-Nahoum S, Medzhitov R. Role of toll-like receptors in tissue repair and tumorigenesis Biochem Biokhimiia 2008; 73: 555-561.

15. Abreu MT. Toll-like receptor signalling in the intestinal epithelium: how bacterial recognition shapes intestinal function. Nat Rev Immunol 2010; 10: 131-144.

16. Martin-Villa JM, Ferre-Lopez S, Lopez-Suarez JC, Corell A, Perez-Blas M, Arnaiz-Villena A Cell surface phenotype and ultramicroscopic analysis of purified human enterocytes: a possible antigen-presenting cell in the intestine. Tissue Antigens 1997; 50: 586-592.

17. Belmonte L, Beutheu Youmba S, Bertiaux-Vandaele N, Antonietti M, Lecleire S, Zalar A et al. Role of toll like receptors in irritable bowel syndrome: differential mucosal immune activation according to the disease subtype. PLoS One 2012; 7: e42777.

18. Wang EL, Qian ZR, Nakasono M, Tanahashi T, Yoshimoto K, Bando Y et al. High expression of Toll-like receptor $4 /$ myeloid differentiation factor 88 signals correlates with poor prognosis in colorectal cancer. Brit J Cancer 2010; 102: 908-915.

19. Fukata M, Chen A, Vamadevan AS, Cohen J, Breglio K, Krishnareddy S et al. Toll-like receptor-4 promotes the development of colitis-associated colorectal tumors. Gastroenterology 2007; 133: 1869-1881.

20. Yu LC, Flynn AN, Turner JR, Buret AG. SGLT-1-mediated glucose uptake protects intestinal epithelial cells against LPS-induced apoptosis and barrier defects: a novel cellular rescue mechanism? FASEB J 2005; 19: 1822-1835.

21. Chin AC, Flynn AN, Fedwick JP, Buret AG. The role of caspase-3 in lipopolysaccharidemediated disruption of intestinal epithelial tight junctions. Can J Physiol Pharmacol 2006; 84 1043-1050.

22. Ruemmele FM, Beaulieu JF, Dionne S, Levy E, Seidman EG, Cerf-Bensussan N et al. Lipopolysaccharide modulation of normal enterocyte turnover by toll-like receptors is mediated by endogenously produced tumour necrosis factor alpha. Gut 2002; 51: 842-848.

23. Grondin V, Seksik P, Dumont S, Thomas G, Trugnan G, Flejou JF et al. Regulation of colon cancer cell proliferation and migration by MD-2 activity. Innate Immun 2011; 17: 414-422.

24. da Silva Correia J, Soldau K, Christen U, Tobias PS, Ulevitch RJ. Lipopolysaccharide is in close proximity to each of the proteins in its membrane receptor complex. transfer from CD14 to TLR4 and MD-2. J Biol Chem 2001; 276: 21129-21135.

25. Dunzendorfer S, Lee HK, Soldau K, Tobias PS. TLR4 is the signaling but not the lipopolysaccharide uptake receptor. J Immunol 2004; 173: 1166-1170.

26. Cuschieri J, Billgren J, Maier RV. Phosphatidylcholine-specific phospholipase C (PC-PLC) is required for LPS-mediated macrophage activation through CD14. J Leukoc Biol 2006; 80: 407-414.

27. Triantafilou M, Miyake K, Golenbock DT, Triantafilou K. Mediators of innate immune recognition of bacteria concentrate in lipid rafts and facilitate lipopolysaccharide-induced cell activation. J Cell Sci 2002; 115: 2603-2611.
28. Colell A, Morales A, Fernandez-Checa JC, Garcia-Ruiz C. Ceramide generated by acidic sphingomyelinase contributes to tumor necrosis factor-alpha-mediated apoptosis in human colon HT-29 cells through glycosphingolipids formation. Possible role of ganglioside GD3. FEBS Lett 2002; 526: 135-141.

29. Kim M, Datta A, Brakeman P, Yu W, Mostov KE. Polarity proteins PAR6 and aPKC regulate cell death through GSK-3beta in 3D epithelial morphogenesis. J Cell Sci 2007; 120: 2309-2317.

30. Garcia-Barros M, Coant N, Truman JP, Snider AJ, Hannun YA. Sphingolipids in colon cancer. Biochim Biophys Acta 2014; 1841: 773-782.

31. Hertervig E, Nilsson A, Nilbert M, Duan RD. Reduction in alkaline sphingomyelinase in colorectal tumorigenesis is not related to the APC gene mutation. Int J Colorectal Dis 2003: 18: $309-313$

32. Ma L, Tao Y, Duran A, Llado V, Galvez A, Barger JF et al. Control of nutrient stress-induced metabolic reprogramming by PKCzeta in tumorigenesis. Cell 2013; 152 : 599-611.

33. Nenci A, Becker C, Wullaert A, Gareus R, van Loo G, Danese S et al. Epithelial NEMO links innate immunity to chronic intestinal inflammation. Nature 2007; 446: 557-561.

34. Edelblum KL, Washington MK, Koyama T, Robine S, Baccarini M, Polk DB. Raf protects against colitis by promoting mouse colon epithelial cell survival through NF-kappaB. Gastroenterology 2008; 135: 539-551.

35. Fukata M, Chen A, Klepper A, Krishnareddy S, Vamadevan AS, Thomas LS et al. Cox-2 is regulated by Toll-like receptor-4 (TLR4) signaling: role in proliferation and apoptosis in the intestine. Gastroenterology 2006; 131: 862-877.

36. Rakoff-Nahoum S, Medzhitov R. Regulation of spontaneous intestinal tumorigenesis through the adaptor protein MyD88. Science 2007; 317: 124-127.

37. Nambiar PR, Girnun G, Lillo NA, Guda K, Whiteley HE, Rosenberg DW. Preliminary analysis of azoxymethane induced colon tumors in inbred mice commonly used as transgenic/ knockout progenitors. Int J Oncol. 2003; 22: 145-150.

38. Nagamine CM, Rogers AB, Fox JG, Schauer DB. Helicobacter hepaticus promotes azoxymethane-initiated colon tumorigenesis in BALB/c-IL10-deficient mice. Int $J$ Cancer 2008; 122: 832-838

39. Kim HM, Park BS, Kim JI, Kim SE, Lee J, Oh SC et al. Crystal structure of the TLR4-MD-2 complex with bound endotoxin antagonist Eritoran. Cell 2007; 130: 906-917.

40. Yeh YC, Ko WJ, Chan KC, Fan SZ, Tsai JC, Cheng YJ et al. Effects of eritoran tetrasodium, a Toll-like receptor 4 antagonist, on intestinal microcirculation in endotoxemic rats. Shock2012; 37: 556-561

41. Araki Y, Sugihara H, Hattori T. In vitro effects of dextran sulfate sodium on a Caco-2 cell line and plausible mechanisms for dextran sulfate sodium-induced colitis. Oncol Rep 2006; 16 : 1357-1362.

42. Chen R, Luo FK, Wang YL, Tang JL, Liu YS. LBP and CD14 polymorphisms correlate with increased colorectal carcinoma risk in Han Chinese. World J Gastroenterol 2011; 17 2326-2331.

43. Eyking A, Ey B, Runzi M, Roig Al, Reis H, Schmid KW et al. Toll-like receptor 4 variant D299G induces features of neoplastic progression in Caco-2 intestinal cells and is associated with advanced human colon cancer. Gastroenterology 2011; 141: 2154-2165.

44. Pimentel-Nunes P, Teixeira AL, Pereira C, Gomes M, Brandao C, Rodrigues C et al. Functional polymorphisms of Toll-like receptors 2 and 4 alter the risk for colorectal carcinoma in Europeans. Dig Liver Dis 2013; 45: 63-69.

45. Fukata M, Shang L, Santaolalla R, Sotolongo J, Pastorini C, Espana C et al. Constitutive activation of epithelial TLR4 augments inflammatory responses to mucosal injury and drives colitis-associated tumorigenesis. Inflamm Bowel Dis 2011; 17: 1464-1473.

46. Santaolalla R, Sussman DA, Ruiz JR, Davies JM, Pastorini C, Espana CL et al. TLR4 activates the beta-catenin pathway to cause intestinal neoplasia. PLoS One 2013; 8: e63298.

47. Carpenter S, O'Neill LA. Recent insights into the structure of Toll-like receptors and posttranslational modifications of their associated signalling proteins. Biochem J 2009; 422: $1-10$.

48. Czerkies M, Borzecka K, Zdioruk MI, Plociennikowska A, Sobota A, Kwiatkowska K. An interplay between scavenger receptor $A$ and $C D 14$ during activation of $J 774$ cells by high concentrations of LPS. Immunobiology 2013; 218: 1217-1226.

49. Cario E, Rosenberg IM, Brandwein SL, Beck PL, Reinecker HC, Podolsky DK. Lipopolysaccharide activates distinct signaling pathways in intestinal epithelial cell lines expressing Toll-like receptors. J Immunol 2000; 164: 966-972.

50. Abreu MT, Vora P, Faure E, Thomas LS, Arnold ET, Arditi M. Decreased expression of Tolllike receptor-4 and MD-2 correlates with intestinal epithelial cell protection against dysregulated proinflammatory gene expression in response to bacterial lipopolysaccharide. J Immunol 2001; 167: 1609-1616.

51. Suzuki M, Hisamatsu T, Podolsky DK. Gamma interferon augments the intracellular pathway for lipopolysaccharide (LPS) recognition in human intestinal epithelial cells through coordinated up-regulation of LPS uptake and expression of the intracellular Toll-like receptor 4-MD-2 complex. Infect Immun 2003; 71: 3503-3511.

52. Yagi S, Takaki A, Hori T, Sugimura K. Enteric lipopolysaccharide raises plasma IL-6 levels in the hepatoportal vein during noninflammatory stress in the rat. Fukuoka Acta Med 2002; 93 38-52. 
53. Zanoni I, Ostuni R, Capuano G, Collini M, Caccia M, Ronchi AE et al. CD14 regulates the dendritic cell life cycle after LPS exposure through NFAT activation. Nature 2009; 460: 264-268.

54. Dobrovolskaia MA, Vogel SN. Toll receptors, CD14, and macrophage activation and deactivation by LPS. Microbes Infect 2002; 4: 903-914.

55. Hsu LC, Park JM, Zhang K, Luo JL, Maeda S, Kaufman RJ et al. The protein kinase PKR is required for macrophage apoptosis after activation of Toll-like receptor 4. Nature 2004; $\mathbf{4 2 8}$ 341-345.

56. Rallabhandi P, Bell J, Boukhvalova MS, Medvedev A, Lorenz E, Arditi M et al. Analysis of TLR4 polymorphic variants: new insights into TLR4/MD-2/CD14 stoichiometry, structure, and signaling. J Immunol 2006; 177: 322-332.

57. Wang EL, Qian ZR, Nakasono M, Tanahashi T, Yoshimoto K, Bando Y et al. High expression of Toll-like receptor 4 /myeloid differentiation factor 88 signals correlates with poor prognosis in colorectal cancer. Br J Cancer 2010; 102: 908-915.

58. Uronis JM, Muhlbauer M, Herfarth HH, Rubinas TC, Jones GS, Jobin C. Modulation of the intestinal microbiota alters colitis-associated colorectal cancer susceptibility. PLoS One 2009; 4: e6026.

59. Wu LL, Chiu HD, Peng WH, Lin BR, Lu KS, Lu YZ et al. Epithelial inducible nitric oxide synthase causes bacterial translocation by impairment of enterocytic tight junctions via intracellular signals of Rho-associated kinase and protein kinase C zeta. Crit Care Med 2011; 39: 2087-2098.

60. Huang CY, Hsiao JK, Lu YZ, Lee TC, Yu LC. Anti-apoptotic PI3K/Akt signaling by sodium/ glucose transporter 1 reduces epithelial barrier damage and bacterial translocation in intestinal ischemia. Lab Invest 2011; 91: 294-309.

61. Yu LC, Turner JR, Buret AG. LPS/CD14 activation triggers SGLT-1-mediated glucose uptake and cell rescue in intestinal epithelial cells via early apoptotic signals upstream of caspase-3. Exp Cell Res 2006; 312: 3276-3286.

62. Chen J, Winston JH, Sarna SK. Neurological and cellular regulation of visceral hypersensitivity induced by chronic stress and colonic inflammation in rats. Neuroscience 2013; 248C: 469-478.

63. Sato $T$, Stange DE, Ferrante M, Vries RG, Van Es JH, Van den Brink $S$ et al. Long-term expansion of epithelial organoids from human colon, adenoma, adenocarcinoma, and Barrett's epithelium. Gastroenterology 2011; 141 1762-1772.

64. Huang CY, Kuo WT, Huang YC, Lee TC, Yu LC. Resistance to hypoxia-induced necroptosis is conferred by glycolytic pyruvate scavenging of mitochondrial superoxide in colorectal cancer cells. Cell Death Dis 2013; 4: e622.

Supplementary Information accompanies this paper on Cell Death and Differentiation website (http://www.nature.com/cdd) 